\title{
La respuesta del sistema de Naciones Unidas ante la situación de crisis prolongada en Haití
}

\author{
The response of the United Nation System \\ to the protraded crisis in Haiti
}

Jordi Feo VALERo

Doctor en Derecho. Universidad de Valencia

Colaborador de Human Rights Research and Education Centre. Universidad de Ottawa

jordifeo@gmail.com

\begin{abstract}
Resumen: Haití se ha erigido en un factor de inestabilidad regional que ha derivado en su consideración por parte del Consejo de Seguridad de las Naciones Unidas como una amenaza a la paz y a la seguridad internacionales a lo largo de los últimos 25 años. Este artículo pretende analizar la importancia de la actuación internacional Ilevada a cabo en Haití, así como si la respuesta del sistema de las Naciones Unidas ante las crisis haitianas ha garantizado unas condiciones de paz y estabilidad que han servido de base para importantes avances en otros ámbitos.
\end{abstract}

Palabras clave: Sistema de Naciones Unidas, Crisis prolongada, Derecho Internacional, MINUSTAH, Operaciones de Mantenimiento de la Paz, Haití.

\begin{abstract}
Haiti has emerged as a factor of regional instability that led to its consideration by the United $\mathrm{Na}$ tions Security Council as a threat to peace and international security over the past 25 years. This work aims to analyze the importance of the international action undertaken in Haiti and determine if the response of the United Nations System towards the Haitian crisis has been able to create an environment of peace and stability that has provided the basis for significant progress in other areas.
\end{abstract}

Keywords: United Nations System, Protracted crisis, International Law, MINUSTAH, Peacekeeping Mission, Haiti.
Résumé : Haïti a émergé comme un facteur d'instabilité régionale qui a conduit à sa considération par le Conseil de Sécurité des Nations Unies comme une menace à la paix et la sécurité internationales pendant les derniers 25 ans. Cet article vise à analyser l'importance de l'action internationale menée en Haïti, ainsi que si la réponse du système des Nations Unies aux crises haïtiennes a été capable de garantir des conditions de paix et de stabilité qui ont servi de base pour des progrès significatifs dans d'autres domaines.

Mots clés : Système des Nations Unies, Crise prolongée, Droit International, MINUSTAH, Mission de Maintien de la Paix, Haïti.

\footnotetext{
Sumario: 1. PLANTEAMIENTO DEL CASO: EL COMPROMISO DE LAS NACIONES UNIDAS CON LA CONSOLIDACIÓN DE LA PAZ, LA DEMOCRACIA Y LOS DERECHOS HUMANOS EN HAITÍ. 2. ANTECEDENTES BÁSICOS: LOS ESFUERZOS DE LA COMUNIDAD INTERNACIONAL PARA DAR UNA RESPUESTA A LAS SITUACIONES ACAECIDAS. 2.a La Misión Civil Internacional en Haití: MICIVIH (1993-2000). 2.b La Misión de las Naciones Unidas en Haití: UNIMH (1993-1996) y el controvertido despliegue de una fuerza multilateral en el año 1994. 2.c La Misión de Apoyo de las Naciones Unidas en Haití: UNSMIH (1996-1997). 2.d La Misión de Transición de las Naciones Unidas en Haití: UNTMIH (1997). 2.e La Misión de Policía Civil de las Naciones Unidas en Haití: MIPONUH (1997-2000), 2.f La Misión Civil Internacional de Apoyo en Haití: MICAH (marzo 2000-febrero de 2001). 2.g El apoyo unánime al despliegue de una Fuerza Multinacional Interina en el año 2004. 3. LA MISIÓN DE ESTABILIZACIÓN DE LAS NACIONES UNIDAS EN HAITÍ: MINUSTAH (2004-2016). 3.a La contribución del contingente de Naciones Unidas a la consolidación de la democracia en el país. 3.b La adaptación de los mandatos de la Misión a los cambios de realidades producidos en el transcurso del tiempo sobre el terreno. 3.c. El componente de Derechos Humanos como eje de la Misión de Estabilización de las Naciones Unidas en Haití. 3.d La implicación de las fuerzas armadas españolas en el contingente de la MINUSTAH. 4. CONSIDERACIONES FINALES: ¿ES VÁLIDO EL ACTUAL MODELO DE GESTIÓN DE LAS NACIONES UNIDAS FRENTE A LA SITUACIÓN HAITIANA?
} 


\section{Planteamiento del caso: el compromiso de las Naciones Unidas CON LA CONSOLIDACIÓN DE LA PAZ, LA DEMOCRACIA Y LOS DERECHOS HUMANOS EN HAITÍ}

Haití se ha erigido en un factor de inestabilidad regional que ha derivado en su consideración por parte del Consejo de Seguridad de las Naciones Unidas ${ }^{1}$ como una amenaza a la paz y a la seguridad internacionales a lo largo de los años. En este sentido, situaciones tan dispares como el derrocamiento de un gobierno legítimamente electo ${ }^{2}$, la vulneración de los derechos humanos ${ }^{3}$ o el desplazamiento de personas ${ }^{4}$ han sido el detonante de la invocación en diferentes ocasiones desde los años 90 hasta nuestros días del capítulo VII de la Carta de San Francisco 5 .

La presencia internacional en el país bajo el paraguas de la ONU tiene su origen en la organización de las primeras elecciones libres y democráticas celebradas en Haití el 16 de diciembre de 1990. Este hito en la historia del país fue el desencadenante de las diferentes intervenciones llevadas a cabo por el sistema de las Naciones Unidas y que alcanzaron su punto álgido con la aprobación en el año 2004 de la Misión de Estabilización de las Naciones Unidas en Haití, Misión que continúa presente en el país doce años después $^{6}$.

Los años 2014 y 2015 estuvieron marcados por el inicio del proceso de reflexión sobre la pertinencia de reconfigurar la MINUSTAH con vistas a una posible reducción e incluso retirada del contingente militar de las Naciones Unidas en el país. Así pues, el 24 de marzo de 2014, el Consejo de Seguridad,

1 García, R. y López-JaCoiste DíAz, E., La reforma institucional, Universidad Complutense de Madrid, Unidad de Investigación sobre Seguridad y Cooperación Internacional-UNISCI Discussion Papers, $\mathrm{n}^{\circ}$ 10, enero 2006.

2 S/PV.3376, Consejo de Seguridad, 3376 a sesión, 6 de mayo de 1994.

3 S/RES/1529 (2004), Consejo de Seguridad, 4919ª sesión, 29 de febrero de 2004.

4 S/RES/841(1993), Consejo de Seguridad, 3238ª sesión, 16 de junio de 1993.

5 Esteve Moltó, J.E., «La inacción del Consejo de Seguridad ante la amenaza a la paz y seguridad internacionales: El caso de Birmania», Anuario Español de Derecho Internacional, XXVI (2010), pp. 111-141. Autores como Esteve Moltó o Genser afirman que el hecho de calificar una determinada situación como una amenaza a la paz es una cuestión política que será determinada por el Consejo. Esta casuística producir la paradoja de que dos situaciones idénticas puedan ser consideradas en algunos casos como amenaza a la paz y a la seguridad internacionales y en otros no.

6 Feo Valero, J., Haití, un difícil equilibrio entre el derecho internacional, los derechos bumanos y el desarrollo, Tesis doctoral, Programa de Doctorado: Derechos Humanos, Democracia y Justicia Internacional, Universitàt de València, Valencia, 2015, pp. 233-245. 
examinó en su sesión matinal cinco opciones para la reconfiguración de la Misión más allá del año 2016 .

Las opciones que se barajaron abarcaron distintos escenarios entre los que se incluyeron la designación de un enviado especial de las Naciones Unidas para asesorar en la buena gobernanza política, el establecimiento de una misión política especial manteniendo la capacidad de desarrollar la policía nacional haitiana, la creación de una nueva misión de mantenimiento de la paz con un rol esencialmente político y una reducción sustancial de los efectivos sobre el terreno, el establecimiento de una nueva operación de mantenimiento de la paz más reducida y con menos presencia de policía y militares de las Naciones Unidas o una reducción del actual mandato de mantenimiento de la paz ${ }^{8}$. Sin embargo, a pesar de la iniciativa adoptada en este sentido y ante la falta de acuerdo a la hora de determinar cuál era la mejor opción para el país, en fecha 13 de octubre de 2016, el Consejo de Seguridad de las Naciones Unidas decidió prorrogar hasta el 15 de abril 2017 el mandato de la MINUSTAH manteniendo el número de efectivos en el país ${ }^{9}$. Conviene destacar asimismo, que esta resolución, dada la falta de consenso en el seno del Consejo de Seguridad, deja la puerta abierta a la posibilidad de «la posible retirada de la MINUSTAH y la transición hacia una presencia futura de las Naciones Unidas que comenzaría no antes del 15 de abril de $2017 \gg^{10}$. Esta iniciativa puso de manifiesto, sobre todo a través del hecho de no reducir ni los efectivos de la MINUSTAH ni el componente de policía respecto de las anteriores prórrogas de los años $2014^{11}$ y $2015^{12}$, las dudas que exis-

7 S/PV.7147, Consejo de Seguridad, 7147ª sesión, Lunes 24 de marzo de 2014, Nueva York.

8 S/2014/162, Informe del Secretario General sobre la misión de estabilización de las Naciones Unidas en Haití, 7 de marzo de 2014, párrafos 54-62.

9 S/RES/2316 (2016), Consejo de Seguridad, 7799ª sesión, 13 de octubre de 2016.

10 S/RES/2316 (2016), op. cit., párrafo 4.

11 S/RES/2180 (2014), Consejo de Seguridad, 7277 a sesión, 14 de octubre de 2014; S/RES/2243 (2015), Consejo de Seguridad, 7534 a sesión, 14 de octubre de 2015. Tanto la resolución 2180 (2014) en su párrafo 2 como la 2243 (2015) en su párrafo 2 establecen que la dotación total máxima de la MINUSTAH sea de 2.370 efectivos y un componente de policía de hasta 2.601 efectivos.

12 S/RES/2243 (2015), op. cit., párrafo 3. ORGANIZACIÓN DE LOS Estados AMERICANOS, C-203/01, «Secretario General de la OEA establece grupo de amigos de Haití», 2 de octubre de 2001. La negociación de la resolución giró en torno a las dos posturas sostenidas por Francia y EE.UU. Francia, por su parte planteó una serie de propuestas de máximos en la que sugería la renovación del mandato de la MINUSTAH por un periodo inferior al año, la reducción de efectivos a partir de junio y la mención expresa de que esta renovación sería la última. Ante esta postura el resto de integrantes del conocido como Grupo de Amigos de Haití rechazó la misma, lo que obligó a Francia ante su aislamiento, a aceptar las propuestas de compromiso presentadas por EE.UU. como «penholder». 
tían en el seno del Consejo de Seguridad cuando aprobaron la resolución 2243 (2015) sobre las capacidades de Haití de asegurar la estabilidad y la alternancia democrática con sus propios recursos. Dudas que quedarían confirmadas con la celebración de las elecciones presidenciales diez días después y la reciente resolución del Consejo de Seguridad 2316 (2016) a la que hemos hecho referencia.

Desgraciadamente, en el año 2015, cuando el país parecía que iba a consolidar definitivamente la alternancia democrática como norma de juego en la dirección del Estado ${ }^{13}$, las elecciones presidenciales, cuya primera vuelta se llevó a cabo el 25 de octubre ${ }^{14}$, no pudieran culminar en la conformación de una presidencia democrática electa. Tras las acusaciones de fraude electoral llevadas a cabo por la alianza opositora y la creciente escalada del clima de tensión y violencia en el país, las autoridades electorales de Haití decidieron posponer la segunda vuelta de las elecciones ante la negativa del Sr. Jude Célestin, candidato que había quedado en segundo lugar por detrás del oficialista Sr. Jovenel Moise, a concurrir a la segunda vuelta de las elecciones ${ }^{15}$. A pesar de este bloqueo constitucional, los diferentes actores políticos del país, con la intermediación de la comunidad internacional, han sido capaces de llegar un acuerdo para la formación de un gobierno provisional encabezado por el presidente del Senado haitiano, Sr. Jocelerme Privert ${ }^{16}$, encargado de organizar las elecciones para el 24

13 S/2015/667, Secretario General, Informe del Secretario General sobre la Misión de Estabilización de las Naciones Unidas en Haití, 31 de agosto de 2015, párrafo 15. Durante el período de que se informa, el entorno de seguridad siguió en general estable y fue mucho más tranquilo y menos violento que en los anteriores ciclos electorales. No se registraron aumentos de la inseguridad ni la violencia en los departamentos de los que se retiró el componente militar, entre ellos los de Centro, Artibonite y partes del Oeste.

14 De acuerdo con las informaciones proporcionadas por las Misiones de Observación Electoral desplegadas en el país (UE, OEA, Parlatina [promovida por Canadá] y CARICOM) y en especial la MOE-UE presidida por la eurodiputada española Elena Valenciano, la primera vuelta de las elecciones se llevó a cabo en un clima de calma y tranquilidad con una mejorada organización de los comicios en todos los sentidos.

15 De acuerdo con las estimaciones obtenidas por la MOE-UE, el candidato del partido PHTK del Presidente Martelly, Jovenel Moïse, habría obtenido en torno al 35\% de los votos y Jude Célestin de LAPEH el 23\%, pasando estos dos candidatos a la segunda vuelta. El Conseil Electoral Provisoire publicó posteriormente sus resultados en los que otorgaba a Moïse el 32,76\% de los votos y a Célestin el $25,29 \%$, cifras que si bien no coincidían exactamente con las estimaciones de la MOE-UE en nada afectaba a la determinación de los contendientes que debían competir en la segunda vuelta de las elecciones presidenciales.

16 En fecha 14 de febrero de 2016 el presidente del Senado haitiano, Jocelerme Privert, fue elegido por la Asamblea Nacional como el jefe de Estado interino. La sesión duró más de diez horas y fue necesaria una segunda votación para que obtuviera la mayoría de los votos de la Asamblea Nacional. 
de abril con vistas a la instalación del nuevo presidente el 14 de mayo de $2016^{17}$. Sin embargo, dada la interinidad del Gobierno en funciones y las dificultades de la clase política haitiana para llegar a acuerdos, la fecha de la celebración de la repetición de «las elecciones presidenciales de 2015 y las elecciones legislativas, junto con la primera ronda de elecciones para una tercera parte de los escaños del Senado cuyos titulares finalizarán su mandato en enero de $2017 \gg^{18}$ se aplazó finalmente al 9 de octubre de $2016^{19}$. Finalmente, y tras el paso del huracán Matthew, hubo que posponer nuevamente la contienda electoral cuya nueva fecha prevista de celebración será previsiblemente el 20 de noviembre de $2016^{20}$.

\section{ANTECEDENTES BÁSICOS: LOS ESFUERZOS DE LA COMUNIDAD}

\section{INTERNACIONAL PARA DAR UNA RESPUESTA A LAS SITUACIONES ACAECIDAS}

Entre los años 1993 y 2016, el Consejo de Seguridad ha autorizado en dos ocasiones el despliegue de Fuerzas Multinacionales con el fin de dotarse de la flexibilidad para poder llevar a cabo actuaciones en Haití tendentes a revertir situaciones determinadas susceptibles de suponer una amenaza a la paz y a la seguridad internacionales. Para el Consejo de Seguridad se trata de un instrumento muy útil ya que, aunque su despliegue es autorizado por el mismo, su operatividad no se ve sometida a la dirección de las Naciones Unidas al otorgarse el mando de la misma a un país. La implementación de este tipo de iniciativas no puede considerarse como operaciones de mantenimiento de la paz en tanto que conlleva una actuación militar extranjera que no se encuentra bajo el mandato de las Naciones Unidas, aunque cuente con su beneplácito ${ }^{21}$.

Estas Fuerzas Multilaterales desplegadas en momentos de especial dificultad en Haití permitieron a la ONU, como veremos a continuación, dotarse de una herramienta ágil y operativa de cara al establecimiento de la bases necesarias para el posterior despliegue de las operaciones de mantenimiento de la paz lideradas por las Naciones Unidas. En este periodo de tiempo se han auto-

17 S/2016/225, Secretario General, Informe del Secretario General sobre la Misión de Estabilización de las Naciones Unidas en Haití, 8 de marzo de 2016, párrafo 12.

18 S/RES/2316 (2016), op. cit., p. 1.

19 S/2016/753, Informe del Secretario General sobre la Misión de Estabilización de las Naciones Unidas en Haití, 31 de agosto de 2016, párrafo 2.

20 Conseil Electoral Provisoire, «Calendrier électoral 2016-2017 révise», 14 de octubre de 2016, apartado 142, p. 4.

21 Ramón, Chornet, C., El Derecho Internacional Humanitario ante los nuevos conflictos armados, Tirant Lo Blanch Monografías, 2002, pp. 319-354. 
rizado varias misiones de las Naciones Unidas en Haití con presencia de componentes extranjeros ${ }^{22}$. En todas y cada una de ellas, el Consejo de Seguridad ha querido dejar patente su apuesta por la resolución de las crisis producidas poniendo de relieve su compromiso con la seguridad y los derechos humanos.

\section{a) La Misión Civil Internacional en Haití: MICIVIH (1993-2000)}

La Misión Civil Internacional en Haití (MICIVIH) fue creada a petición del Presidente Aristide como consecuencia del golpe de Estado producido en Haití en 1991. Su objetivo era el de controlar la situación de los derechos humanos en el país. Esta iniciativa fue ideada conjuntamente por las Naciones Unidas y la Organización de los Estados Americanos. La importancia de la MICIVIH radica en que es la primera misión conjunta entre una organización regional, la Organización de los Estados Americanos (OEA) y la Organización de las Naciones Unidas (ONU) ${ }^{23}$.

Esta iniciativa puso de manifiesto que era posible implementar una operación conjunta entre las Naciones Unidas y otra organización regional dejando de lado los protagonismos y las dificultades de coordinación sobre el terreno ${ }^{24}$. El 20 de abril de 1993, la Asamblea General de las Naciones Unidas aprobó la Resolución 47/20 B ${ }^{25}$, por la cual se autorizaba el despliegue del contingente de Naciones Unidas en la MICIVIH junto con la OEA.

Hay que indicar que, a pesar de que esta misión conjunta fuera calificada de éxito en términos de cooperación regional ${ }^{26}$, los primeros en reaccionar

22 Iglesias, Velasco, A. J., «El marco jurídico de las operaciones de mantenimiento de la paz de las Naciones Unidas», Foro, Nueva época, n 1 (2005), pp. 127-177.

Debemos tener en consideración el hecho de que no existe una definición oficial adoptada por las Naciones Unidas de lo que debe entenderse por OMP. Tal y como explica el profesor Alfonso J. Iglesias Velasco estas misiones no se encuentran recogidas en la Carta de las Naciones Unidas, sino que fueron surgiendo con el transcurso del tiempo para hacer frente a determinadas necesidades detectadas, ya que era necesario disponer de alguna herramienta que permitiera dar cumplimiento a lo establecido en la Carta de San Francisco.

23 MiLET, P., «El rol de la OEA. El difícil camino de prevención y Resolución de conflictos a nivel regional», Pensamiento Propio, no 19, Cries, Buenos Aires (enero-junio 2004), pp. 143-181.

Centro de Noticias de la OEA-S-001, Declaración del Secretario General de la ONU ante el Consejo Permanente de la OEA, Comunicado de prensa, 12 de febrero de 2013. Disponible en <www.oas.org/es/centro_noticias/comunicado_prensa.asp? sCodigo=S-001>.

24 Peck, C., Sustainable Peace. The Role of the UN and Regional Organizations in Preventing Conflict, Carnegie Commission on Preventing Deadly Conflict series, Rowman and Littlefield Publishers, Maryland, 1998, p. 149.

25 A/RES/47/20 B, Asamblea General de las Naciones Unidas, 20 de abril de 1993.

26 PECK, C., op. cit., p. 149. 
ante la situación que se produjo en el país fueron la Organización de los Estados Americanos. Esta Organización envió un grupo de 18 observadores con el objetivo de contribuir a la reducción de la violencia en general y al respeto de los derechos humanos, cooperar con la distribución de la ayuda humanitaria y evaluar los progresos para la solución política de la crisis en Haití. La Misión Civil de la OEA inició sus labores a mediados de septiembre de 1992. Sin embargo, tres meses después de su despliegue, el gobierno haitiano consideró que la Misión no tenía base legal, por lo que les conminó a abandonar el país ${ }^{27}$.

Fue a raíz de este contratiempo que el Consejo Permanente de la OEA decidió, mediante la Resolución del 10 de noviembre de $1992^{28}$, solicitar a las Naciones Unidas que participase en la Misión Civil de la OEA, concreción que se produciría con la resolución del Consejo de Seguridad $841(1993)^{29}$. De acuerdo con la Resolución 47/20B, la labor de esta misión era la de verificar el cumplimiento de las labores internacionales de Haití en materia de derechos humanos, prestando especial atención al respeto de los derechos a la vida, la integridad y seguridad de la persona, la libertad personal, de expresión y de asociación ${ }^{30}$. En el momento álgido de la Misión, la MICIVIH llegó a contar con un total de 220 empleados internacionales, entre los que se encontraban 102 observadores de Derechos Humanos, de los cuales 26 eran voluntarios de las Naciones Unidas ${ }^{31}$.

b) La Misión de las Naciones Unidas en Haití: UNIMH (1993-1996) y el controvertido despliegue de una fuerza multilateral en el año 1994

La UNMIH, cuya finalidad era la aplicación de los Acuerdos de Governors Island ${ }^{32}$, tuvo su origen en estos acuerdos de fecha 3 de julio de

27 OEA/Ser.L/V/II.83, «Informe sobre la situación de los derechos humanos en Haití», Doc. 18, 9 marzo 1993.

28 CP/RES. 594 (923/92), Resolución del Consejo Permanente de fecha 10 de noviembre de 1992.

29 Pezzano, L., «La adopción de medidas coercitivas por los organismos regionales: un análisis del artículo 53 de la Carta de las Naciones Unidas a la luz de la práctica de la OEA», Anuario Mexicano de Derecho Internacional, vol. XII, 2012, pp. 292-293. S/RES/841(1993), op. cit.

30 A/RES/47/20 B, op. cit., párrafo 1.

31 Department of Public Information, United Nations, International Civilian Mission in Haiti - MICIVIH, United Nations Peace Keeping, Press Release, 31 August 1996. Disponible en <www.un.org/en/peacekeeping/missions/past/micivih.htm>.

32 Martínez Guillem, R., La detención operativa en la frontera entre el Derecho Internacional Humanitario y el Derecho Internacional de los Derechos Humanos, Tesis doctoral, Programa de Doctorado: Derechos Humanos, Democracia y Justicia Internacional, Universitàt de València, Valencia, 2012, p. 262. 
$1993^{33}$. Esta misión fue la herramienta utilizada por la comunidad internacional para hacer valer lo acordado en esta isla situada en la bahía de Nueva York. Así pues, el Secretario General de las Naciones Unidas, en su informe sobre Haití de fecha 25 de agosto de 1993 (S/2635234), recomendaba al Consejo de Seguridad que autorizara el establecimiento y el envío inmediato, en cuanto se hubieran cumplido las condiciones estipuladas en el acuerdo de Governors Island, de la Misión de las Naciones Unidas en Haití. Posteriormente, en su informe $\mathrm{S} / 26480^{35}$, de fecha 21 de septiembre de 1993, y como respuesta al requerimiento realizado por el Consejo de Seguridad ${ }^{36}$, el Secretario General desgranaba cuáles deberían ser los pormenores de la futura misión, a la par que propone como enviado especial para Haití a la persona al mando de la Misión, el Sr. Dante Caputo.

La Resolución del Consejo de Seguridad 867 (1993) aprobó «el establecimiento y el inmediato envío de la Misión de las Naciones Unidas en Haití (UNMIH) por un periodo de seis meses» ${ }^{37}$. En un primer momento, esta Resolución estableció que la función del componente militar de la UNIMH era la de modernizar las fuerzas armadas, mientras que el de los observadores de la policía de las Naciones Unidas sería el de orientar y asesorar a la policía de Haití en todos los niveles y supervisar la forma en que se llevan a cabo las operaciones de policía. De acuerdo con lo establecido en el párrafo segundo de la Resolución 867 (1993), la Misión de las Naciones Unidas debía estar integrada por 567 observadores de policía de las Naciones Unidas y una unidad de construcción militar con aproximadamente 700 integrantes, incluidos 60 instructores militares. Sin embargo, debido a la falta de cooperación por parte de las autoridades militares del país ${ }^{38}$, la Misión no pudo realizar el despliegue de la totalidad de sus efectivos ni llevar a cabo su mandato.

En el año 1993, en contra de lo establecido en el Acuerdo de Governors Island $^{39}$ el gobierno golpista del General Cédras no permitió el despliegue de la

33 Comisión Interamericana de Derechos Humanos, nº 20/93, Acuerdos de Governors Island, 3 de julio de 1993.

34 S/26352, Informe del Secretario General sobre Haití, 25 de agosto de 1993, párrafo 20.

35 S/26480, Informe del Secretario General sobre Haití, 21 de septiembre de 1993, párrafo 20.

36 S/RES/862 (1993), Consejo de Seguridad, 3272ª sesión, 31 de agosto de 1993.

37 S/RES/867 (1993), Consejo de Seguridad, 3282ª sesión, 23 de septiembre de 1993.

38 Estos extremos son reconocidos por el Secretario General en sus informes 54, 593, 742, 765, 828, 871, 1012, 1143 y 1180 de 1994.

39 Acuerdos de Governors Island de fecha 3 de julio de 1993 y Pacto de Nueva York de fecha 16 de julio de 1993; A/47/975, S/26063, Asamblea General, Situación de la democracia y los derechos humanos en Haití, 12 de julio de 1993. 
Misión, lo que provocó que se invocara el capítulo VII de la Carta de las Naciones Unidas. El Consejo de Seguridad, en su sesión celebrada el 13 de octubre de 1993, se mostró «profundamente preocupado por los obstáculos que siguen impidiendo la llegada de la Misión de las Naciones Unidas en Haití (UNMIH), enviada en cumplimiento de la Resolución 867 (1993), y por el hecho de que las Fuerzas Armadas de Haití no hayan cumplido su obligación de permitir que la Misión dé comienzo a su labor» ${ }^{40}$.

Este órgano, a través de las Resoluciones 873 (1993) y 940 (1994) estableció una serie de medidas coercitivas, por las cuales se decretaba en un primer lugar un embargo sobre Haití ${ }^{41}$, para después autorizar la creación de una fuerza multinacional ${ }^{42}$, con la facultad de recurrir a «todos los medios necesarios» ${ }^{43}$ para facilitar la partida de Haití de los dirigentes militares, y de este modo hacer cumplir los Acuerdos de Governors Island ${ }^{44}$. En todo caso, en relación con la Resolución 940 (1994) que autorizó el despliegue, el representante mexicano, Sr. Flores Olea mostró su preocupación por el hecho de que en el proyecto de Resolución no existiera ninguna mención al marco temporal en el que debían desarrollarse las acciones propuestas. Para él, este texto otorgaba «una suerte de «carta en blanco» para que una indefinida fuerza multinacional actúe cuando lo considere conveniente», calificando esta práctica de «altamente peligrosa en el campo de las relaciones internacionales» ${ }^{45}$.

En septiembre de 1994, un primer grupo compuesto por 2.000 militares estadounidenses desembarcaba en Puerto Príncipe, alcanzando el contingente internacional un total de más de 15.600 militares diez días después ${ }^{46}$. Bajo mando y control unificado, dirigido por los Estados Unidos de América, este

40 S/RES/873 (1993), Consejo de Seguridad en su 3291 a sesión, 13 de octubre de 1993. Por su lado la Resolución 841 (1993) establecía el embargo sobre el país.

41 Bennouna, M., «L'embargo dans la pratique des Nations Unies. Radioscopie d'un moyen de pression», Cursos Mediterráneos Bancaja de Derecho Internacional, vol. 1, Aranzadi, Pamplona, 1998, pp. 205-240.

42 Bermejo GARCía, R., El marco jurídico internacional en materia de uso de la fuerza: ambigüedades y limites, Civitas, Madrid, 1993, pp. 109-150.

43 S/RES/940 (1994), op. cit., párrafos 4 y 5.

44 Schachter, O., «The Legality of Pro-Democratic Invasion», American fournal of International Law (AfIL), vol. 78 (1984), p. 650. Algunos autores como Schachter critican como a lo largo de la historia ha quedado patente la cantidad de injusticias y barbaridades que se han cometido por parte de diferentes Estados bajo la bandera de la «causa justa» y la defensa de los valores democráticos.

45 S/PV.3413, Consejo de Seguridad Provisional, 3413 a sesión, 31 de julio de 1994, a las 11.55 horas, Nueva York.

46 S/1994/1143, Informe del Secretario General sobre la cuestión de Haití, 28 de septiembre de 1994. 
contingente llegó a estar integrado por 28 naciones ${ }^{47}$. Esta intervención cumplió con su cometido al forzar la salida de los militares golpistas y establecer las condiciones necesarias para el despliegue de la UNMIH.

Como se puede constatar de la lectura de los debates previos a la adopción de la Resolución $940(1994)^{48}$, la misma no estuvo exenta de polémica al ser varios los países en el seno de las Naciones Unidas los que se posicionaron contra la misma. Sin embargo, dado que ni México, Cuba ${ }^{49}$, Uruguay o Brasil tenían derecho a voto no pudieron hacerlo constar en la votación. La principal crítica consistió en el temor expresado a que el despliegue de la fuerza multinacional se convirtiera en un peligroso precedente ${ }^{50}$. A partir de octubre de 1994, una vez restaurado el gobierno Constitucional en el país, el Consejo de Seguridad modificó el mandato de la misión en dos ocasiones. La primera se realizó a través de la Resolución $940(1994)^{51}$ que, en virtud del capítulo VII de la Carta, autorizó a los Estados Miembros a «integrar una fuerza multinacional bajo mando y control unificados $y$, dentro de ese marco, a recurrir a todos los medios necesarios para facilitar la partida de Haití de los diri-

47 División de Noticias y Medios de Información del Departamento de Información Pública, en colaboración con el Departamento de Operaciones de Paz. Organización de las Naciones Unidas. Disponible en <www.un.org/es/peacekeeping/missions/past/unmih.htm>.

48 S/PV.3413, op. cit.

49 El representante de Cuba alegó que se trataba de un asunto interno del país, por lo que daba a entender que esta actuación suponía una vulneración de su soberanía. Para profundizar sobre el tema puede consultarse:

Micic TAgER, A., «El Consejo de Seguridad de Naciones Unidas y la acción colectiva: La cuestión de la soberanía estatal», Revista Pléyade, n 3, Centro de Análisis e Investigación PolíticaCAIP, Santiago de Chile (2009), pp. 171-200.

50 S/PV.3413, op. cit., pp. 4-7. Respecto de la Resolución 940 (1994) que autorizó el despliegue, el Representante Mejicano, Sr. Flores Olea dijo: «Preocupa, igualmente, que en el proyecto de Resolución no exista mención alguna del marco del tiempo en que se efectuarán las acciones propuestas. Es decir, se otorga una suerte de «carta en blanco» para que una indefinida fuerza multinacional actúe cuando lo considere conveniente. Ésta es una práctica que nos parece altamente peligrosa en el campo de las relaciones internacionales». El representante cubano, Sr. Rodríguez Parrilla denunció la política estadounidense. Representante Cubano: «El régimen militar de facto es expresión de una dictadura creada, sostenida y financiada durante décadas por los Estados Unidos. El golpe de Estado fue resultado de esa política». Por su parte, el Representante Uruguayo matizó que «El Uruguay no apoyará ninguna intervención militar en la hermana República de Haití, sea de naturaleza unilateral o multilateral». Representante brasileño: «El Brasil se abstendrá en la votación».

51 S/RES/940 (1994), Consejo de Seguridad, 3413 a sesión, 31 de julio de 1994, párrafos 9 y 10. S/1994/1180, Report of the Secretary-General on the question concerning Haiti, 18 de octubre de 1994, párrafo tercero. La fuerza multinacional se desplegó en el país el 19 de septiembre de 1994 y fue liderada por los EE.UU. 
gentes militares». Para Alexander Micic, este texto constituyó una Resolución sin precedentes, ya que por primera vez el Consejo «autorizó el retiro de un Gobierno y la restauración de otro en un conflicto que prácticamente no constituía amenaza a otros Estados» $\gg^{52}$.

El nuevo mandato consistía esencialmente en asistir al gobierno democrático en la preservación de un entorno estable y seguro en el país, convertir a las fuerzas armadas en una fuerza profesional y crear un cuerpo separado de policía. Asimismo, ya que deberían trabajar en lograr un entorno propicio para la celebración de elecciones legislativas libres y limpias decidió aumentarse la dotación militar de las Naciones Unidas hasta los 6.000 efectivos.

La segunda modificación del mandato de la Misión se produjo en el año 1995. En esta ocasión fue la Resolución 975 (1995) $)^{53}$ la que consagró el cambio. En este documento, una vez acreditada la existencia de un entorno seguro y estable en el país ${ }^{54}$, se establece la adopción de las medidas necesarias para que la UNMIH asuma las funciones de la fuerza multinacional y complete la transferencia de las mismas, produciéndose el traspaso definitivo de responsabilidades el 31 de marzo de $1995^{55}$. En junio de 1995 tuvieron lugar las elecciones legislativas, mientras que las presidenciales se celebraron el 17 de diciembre de 1995, transfiriéndose el poder a Réné Préval el 7 de febrero de 1996. El Sr.Wlosowiz, delegado de Polonia en el debate sobre «La cuestión de Haití» que tuvo lugar en el seno del Consejo de Seguridad en febrero de 1996, se hizo eco del hecho de que se tratara de «la primera sucesión presidencial democrática en la turbulenta bistoria de Haití ${ }^{56}$. Lo que se olvidó mencionar el delegado polaco es que, si bien es cierto que se produjo una transición democrática bajo el paraguas de la UNMIH, el anterior presidente, Sr. Aristide, se había visto obligado a exiliarse en el año 1991, y no había podido volver al país hasta 1994. El mandato de la UNMIH finalizó el 30 de junio de 1996, de conformidad con lo establecido en la Resolución 1048 $(1996)^{57}$. En febrero de 1996, el Consejo de Seguridad, a través de la Resolución

52 Micic Tager, A., «El Consejo de Seguridad de Naciones Unidas y la acción colectiva: La cuestión de la soberanía estatal», Revista Pléyade, $\mathrm{n}^{\circ} 3$, Centro de Análisis e Investigación Política (CAIP), Santiago de Chile (2009), p. 193.

53 S/RES/975 (1995), Consejo de Seguridad, 3496ª sesión, 30 de enero de 1995, párrafos 7 y 9.

54 S/RES/975 (1995), op. cit., párrafo 5.

55 Sección del Sitio Internet de la ONU de la División de Noticias y Medios de Información del Departamento de Información Pública, en colaboración con el Departamento de Operaciones de Paz. Disponible en <www.un.org/spanish/Depts/dpko/dpko/co_mission/unmih.htm>.

56 S/PV.3638, Consejo de Seguridad, Quincuagésimo primer año, $3638^{a}$ sesión, 29 de febrero de 1996, a las 18.00 horas, Nueva York, p. 9.

57 S/RES/1048 (1996), Consejo de Seguridad, 3638ª sesión, 29 de febrero de 1996, párrafo 9. 
que acabamos de citar, redujo el contingente de la Misión a un total de 1.200 efectivos de la UNMIH y a 300 policías civiles. Por su lado Canadá financió el despliegue de 700 soldados adicionales ${ }^{58}$. Tras su finalización, el Secretario General recomendó una Nueva Misión de las Naciones Unidas en el país ${ }^{59}$.

Las gestiones llevadas a cabo por la UNMIH complementaron aquéllas de los organismos de la ONU que ya se encontraban prestando asistencia humanitaria y asistencia para el desarrollo. Mediante un acuerdo singular en el sistema de la ONU, el Coordinador Humanitario del PNUD/DAH y Coordinador Residente del sistema de la ONU, el Sr. Cristian Ossa, hizo las veces de Representante Especial Adjunto del Secretario General para Haití. ${ }^{60}$

A la finalización de la Misión, el Secretario General desgranó los principales problemas de los que adolecía el sistema haitiano ${ }^{61}$. En su opinión los principales obstáculos a los que debía de enfrentarse el país eran la falta de personal cualificado para integrar los organismos del Estado, la fragilidad del sistema democrático en el país, la necesidad de consolidación de las instituciones y la penuria económica. Asimismo, resaltaba el deber de continuar con la reconstrucción y de mantener la presencia y la asistencia de la comunidad internacional en Haití, ya que el retiro de la fuerza de la ONU podría poner en riesgo los logros realizados hasta ese momento ${ }^{62}$.

\section{c) La Misión de Apoyo de las Naciones Unidas en Haití: UNSMIH (1996-1997)}

Con fecha de 31 de mayo de 1996, el Presidente de Haití, René Préval envió una carta al Secretario General de las Naciones Unidas en la cual expresaba el deseo de Haití de prorrogar la presencia de la fuerza internacional en el país por un periodo adicional de seis meses ${ }^{63}$. En respuesta a esta petición, el Secretario General propuso una nueva operación de menores dimensiones bajo el nombre de Misión de Apoyo de las Naciones Unidas en Haití (UNSMIH).

58 S/1996/416, Informe del Secretario General sobre la Misión de las Naciones Unidas en Haití, 5 de junio de 1996. párrafo octavo.

59 S/1996/416, op. cit., párrafo 34.

60 División de Noticias y Medios de Información del Departamento de Información Pública, en colaboración con el Departamento de Operaciones de Paz. Disponible en <www.un.org/spanish/Depts/dpko/dpko/co_mission/unmih.htm>.

$61 \mathrm{~S} / 1996 / 416$, op. cit.

62 S/1996/416, op. cit., pp. 2-11.

63 S/1996/416, op. cit. 
El mandato de la UNSMIH se fundamentaba en tres pilares: La asistencia al Gobierno de Haití en la profesionalización de la policía, la asistencia a las autoridades haitianas en sus esfuerzos por establecer y capacitar una fuerza nacional policial efectiva y la coordinación de las actividades del sistema de las Naciones Unidas para propiciar la formación institucional, la reconciliación nacional y la rehabilitación económica en Haitíí ${ }^{4}$.

De acuerdo con lo establecido en la Resolución 1063 (1996), la composición inicial de la UNSMIH estaría conformada por 300 funcionarios de policía civil y 600 efectivos $^{65}$. El 13 de noviembre de 1996, el Presidente Préval, solicitó una nueva prórroga ${ }^{66}$. Tras dos prórroga más, recogidas en las Resoluciones 1085 (1996) ${ }^{67}$ y $1086(1996)^{68}$. El 30 de julio de 1997, el Consejo de Seguridad aprobó la Resolución $1123(1997)^{69}$, a través de la cual daba por amortizada la UNSMIH y establecía la Misión de Transición de las Naciones Unidas en Haití (UNTMIH) con un mandato limitado a un solo período de cuatro meses.

El informe emitido por el Secretario General ${ }^{70}$ a la finalización de la Misión puso de manifiesto la dificultad de la tarea emprendida y los problemas que iban surgiendo ante la perspectiva de una retirada de las fuerzas de las Naciones Unidas.

d) La Misión de Transición de las Naciones Unidas en Haití: UNTMIH (1997)

La UNTMIH tuvo su base en el informe del Secretario General S/1997/56471, el cual se hizo eco de la declaración pública realizada por el Presidente Préval, de fecha 14 de mayo de 1997, en la cual consideraba que

64 S/RES/1063 (1996), Consejo de Seguridad, 3676ª sesión, 28 de junio de 1996.

65 S/RES/1063 (1996), op. cit., párrafo 3.

66 S/1996/956, carta de fecha 15 de noviembre de 1996 dirigida al Presidente del Consejo de Seguridad por el Secretario general y Anexo conteniendo la Carta de fecha 13 de noviembre de 1996 dirigida al Secretario General por el Presidente de Haití.

67 S/RES/1085 (1996), Consejo de Seguridad, 3719ª sesión, 29 de noviembre de 1996.

68 S/RES/1086 (1996), Consejo de Seguridad, 3721 a sesión, 5 de diciembre de 1996.

69 S/RES/1123 (1997), Consejo de Seguridad, 3806 a sesión, 30 de julio de 1997.

70 S/1997/564, Informe del Secretario General sobre la Misión de Apoyo de las Naciones Unidas en Haití, 19 de julio de 1997.

71 S/1997/564, Informe del Secretario General sobre la Misión de Apoyo de las Naciones Unidas en Haití, de fecha 19 de julio de 1997, párrafos 33, 34 y 36. 
serían necesarios entre ocho y doce meses ${ }^{72}$ para que la Policía Nacional Haitiana $(\mathrm{PNH})$ pudiera mantener un entorno seguro y estable sin el apoyo internacional.

En este informe de fecha 19 de julio de 1997, el Sr, Kofi Anan, por entonces Secretario General de las Naciones Unidas, recomendó al Consejo de Seguridad que examinara la posibilidad de mantener el apoyo de las Naciones Unidas a la PNH. Además el Secretario General de las Naciones Unidas recogió que, en caso de tomar en consideración su recomendación, el Consejo de Seguridad podría establecer una nueva misión denominada Misión de Transición de las Naciones Unidas en Haití (UNTMIH), y cuyo mandato tendría una duración de cuatro meses. De acuerdo con sus recomendaciones el contingente de la nueva misión estaría compuesto por elementos civiles y militares, en concreto entre 250 y 300 oficiales de la policía civil y entre 50 y 500 efectivos de cuartel general.

Por su lado, el Representante Especial del Secretario General, Enrique ter Horst, seguiría coordinando las actividades del sistema de las Naciones Unidas en Haití encaminadas a promover el desarrollo institucional, la reconciliación nacional y la rehabilitación económica. El Consejo de Seguridad a través de la Resolución $1123(1997)^{73}$, de 30 de julio de 1997, y siguiendo la recomendación del Secretario General, estableció la UNTMIH por un periodo de cuatro meses. El delegado de Kenia, en el debate que se produjo sobre la situación de Haití en el Consejo de seguridad y en el que se trató el tema de la UNTMIH consideró que el periodo establecido para la misión era adecuado:

«Mi delegación también está de acuerdo con la recomendación que el Secretario General formula en su informe en el sentido de que esa fuerza no debe permanecer en Haití demasiado tiempo y que un período de cuatro meses es adecuado» ${ }^{74}$.

En la carta de fecha 29 de octubre de $1997^{75}$, el Presidente Préval, a la vista del inminente fin de la Misión, solicita la partida de todas las fuerzas mi-

S/1996/956, carta de fecha 15 de noviembre de 1996 dirigida al Presidente del Consejo de Seguridad por el Secretario General.

73 S/RES/1123 (1997), Consejo de Seguridad, 3806 a sesión, 30 de julio de 1997.

74 S/PV.3806, Consejo de Seguridad, $3806^{\text {a }}$ sesión, 30 de julio de 1997, Nueva York, p. 11.

75 S/1997/832, Carta de fecha 29 de octubre de 1997 dirigida por el Presidente Réné Préval al Secretario General. 
litares de las Naciones Unidas de Haití, a la vez que insta a continuar con la labor de fortalecimiento de la PNH llevada a cabo por la ONU.

El Consejo de Seguridad, estableció como tareas principales de la misión «ayudar al Gobierno de Haití apoyando la profesionalización de la Policía Nacional Haitiana y contribuyendo a ella, según lo indicado en los párrafos 32 a $39^{76}$ del informe del Secretario General de fecha 19 de julio de 1997»77. Entre las principales tareas de la policía civil se incluía la capacitación de unidades especializadas de la Policía Nacional Haitiana. Estas unidades, una vez reforzadas, tenían como objetivo contribuir a la mejora de la eficacia de la PNH, que se iría desarrollando al mismo tiempo.

En cuanto a la colaboración entre la UNTMIH y el Programa de las Naciones Unidas para el Desarrollo (PNUD) se acordó que ambas instituciones continuarían con las labores de preparación de un programa de tres años de asistencia técnica para proporcionar a la Policía Nacional Haitiana capacidad de alto nivel en materia de ejecución de la ley. Las debilidades detectadas en el informe del Secretario General, ahondaban en lo ya mencionado con respecto de las anteriores misiones, con la peculiaridad de que en septiembre de 1997 la Cámara de Diputados aprobó una disposición que exigía la salida de Haití de todos los cuerpos armados extranjeros ${ }^{78}$, petición que no fue atendida.

\section{e) La Misión de Policía Civil de las Naciones Unidas en Haití: MIPONUH (1997-2000).}

La MIPONUH tiene su origen en el informe del Secretario General S/1997/83279, de fecha 31 de octubre de 1997. Este informe, el último respecto de la UNTMIH, hace balance de la situación del país y comunica que

76 S/1997/564, Informe del Secretario General sobre la Misión de Apoyo de las Naciones Unidas en Haití, 19 de julio de 1997, párrafos 31 a 39.

A modo de resumen de lo indicado en los párrafos 31 a 39 (S/1997/564), podemos decir que el mandato de la UNTMIH consistía en prestar asistencia al Gobierno de Haití, proporcionándole apoyo y contribuyendo a la profesionalización de la Policía Nacional Haitiana tal y como se recoge en la resolución 1123 (1997).

77 S/RES/1123 (1997), op. cit, párrafo 2.

78 S/1997/832, Informe del Secretario General sobre la Misión de Transición de las Naciones Unidas en Haití, 31 de octubre de 1997, párrafo 10.

79 S/1997/832, op. cit., párrafo 40 y anexo II en el que se contiene la carta de fecha 29 de octubre de 1997 dirigida por el presidente Préval al Secretario General de las Naciones Unidas. 
ha iniciado los contactos necesarios para que, en el caso de que el Consejo de Seguridad lo estimara oportuno, establecer en Haití una misión de seguimiento, cuyo cometido principal consistiría una vez más en apoyar a la PNH en su proceso de profesionalización.

La particularidad de esta nueva misión consistía en que estaría compuesta únicamente por un contingente civil, en virtud de la voluntad expresada por el Presidente Préval, en su carta de fecha 29 de octubre de 1997, en la cual afirmaba que ya se podía contemplar la posibilidad de la partida de todas las fuerzas militares de las Naciones Unidas mientras solicita la continuidad del apoyo para la $\mathrm{PNH}$.

«Hoy podemos contemplar con tranquilidad la partida de todas las fuerzas militares de las Naciones Unidas. No obstante, es importante continuar con la labor de fortalecimiento de nuestra policía, que ha estado en acción solamente dos años, especialmente en lo que respecta a la administración de personal y al material, y a la capacitación de sus unidades especializadas para combatir la creciente inseguridad, el bandidaje y el tráfico de drogas» ${ }^{80}$.

En vista de la petición del Presidente haitiano, y tras las consultas realizadas por parte del Secretario General con los Estados Miembros para determinar la disponibilidad del personal necesario, el 20 de noviembre de 1997, se informó del resultado de estas consultas al Consejo de Seguridad. El informe del Secretario General S/1997/832/Add.1 hace referencia a una posible misión complementaria y un marco conceptual de operaciones. Así pues, se solicita formalmente al Consejo de Seguridad que considere la «posibilidad de establecer una misión policial de las Naciones Unidas en Haití, que se denominará MIPONUH, a fin de asistir al Gobierno en sus esfuerzos permanentes por aumentar la profesionalidad de la Policía Nacional Haitiana» ${ }^{81}$. Esta nueva iniciativa estaría compuesta por un máximo de 290 oficiales de policía, incluida una unidad especial de policía de 90 efectivos. También se menciona expresamente la necesidad de estrechar la cooperación entre la MIPONUH y MICIVIH. El representante del gobierno de Chile en el Consejo de Seguridad, quiso dejar clara su posición días antes de adoptar la Resolución que instauró la MIPONUH, respecto

80 S/1997/832, op. cit., Anexo II, párrafo segundo.

81 S/1997/832/Add.1, Informe del Secretario General sobre la misión de las Naciones Unidas para la transición en Haití. 20 de noviembre de 1997. 
de esta iniciativa. Para su gobierno esta misión representaba no solamente la respuesta adecuada a las necesidades que enfrentan el pueblo y Gobierno haitianos, sino que era a la vez a la vez «la expresión del compromiso de las Naciones Unidas con la paz y la seguridad de uno de sus Miembros» ${ }^{82}$.

Una vez analizado este informe, el Consejo de Seguridad estableció la Misión de Policía Civil de las Naciones Unidas en Haití través de la Resolución $1141(1997)^{83}$, de 28 de noviembre de 1997, con la finalidad principal de supervisar, formar y apoyar a la Policía Nacional Haitiana. De acuerdo con lo defendido por Ramón Martínez Guillem en su tesis doctoral «La detención operativa en la frontera entre el Derecho Internacional Humanitario y el Derecho Internacional de los Derechos Humanos»:

«Con la Resolución 1141 de 1997, se llegó a la hasta ese momento más perfeccionada intervención policial en el curso de una OMP, estableciéndose por el Consejo de Seguridad la MIPONUH (United Nations Civilian Police Mission in Haiti), con un componente, como su propio nombre indica, esencialmente policial, destinado a fines de supervisión, formación, apoyo, etc. de la nueva policía haitiana ${ }^{84}$.

Es interesante subrayar, el hecho de que el Consejo de Seguridad se haga eco en esta Resolución de que «para la paz y la seguridad a largo plazo del país es esencial un compromiso sostenido de la comunidad internacional y de las instituciones financieras internacionales de prestar asistencia y apoyo al desarrollo económico, social e institucional de Haitì». Hemos de enmarcar esta referencia a la continuidad de la presencia internacional en Haití como respuesta a la solicitud de salida, llevada a cabo por el parlamento en septiembre de ese mismo año, y por el Presidente del país un mes después ${ }^{85}$.

En relación con la coordinación solicitada por el Secretario General entre MIPONUH y MICIVIH, el Consejo de Seguridad estableció que la Misión de Policía Civil de las Naciones Unidas en Haití se hiciera cargo del personal de la UNTMIH y los activos de propiedad de las Naciones Unidas

\footnotetext{
S/PV.3949, Consejo de Seguridad, 3949ª sesión, 25 de noviembre de 1998, Nueva York, p. 3.

S/RES/1141 (1997), Consejo de Seguridad, 3837 sesión, 28 de noviembre de 1997.

84 Martínez Guillem, R., La detención operativa en la frontera entre el Derecho Internacional Humanitario y el Derecho Internacional de los Derechos Humanos, Tesis doctoral, Programa de Doctorado: Derechos Humanos, Democracia y Justicia Internacional, Universitàt de València, Valencia, 2012, p. 263.

85 S/1997/832, Informe del Secretario general sobre la Misión de Transición de las Naciones Unidas en Haití, de fecha 31 de octubre de 1997.
} 
que necesitara para cumplir su mandato ${ }^{86}$. El Consejo de Seguridad, a la par que afirmó la importancia de un cuerpo de policía nacional profesional, plenamente operacional y autónomo, con una estructura y un tamaño adecuados, capaz de desempeñar todas las funciones policiales, para consolidar la democracia y revitalizar el sistema de administración de justicia, estableció que la misión estaría compuesta por 300 policías civiles (10 más de los sugeridos por el Secretario General), y tendría un mandato limitado a un solo período de un año que terminaría el 30 de noviembre de $1998^{87}$.

Tras el informe del Secretario General $1064(1998)^{88}$, de 11 de noviembre de 1998, en el que se solicitaba una prórroga de la Misión al considerarse que la PNH no estaba plenamente capacitada para llevar a cabo sus funciones con garantías de forma autónoma, el Consejo de Seguridad, a través de la Resolución $1212(1998)^{89}$ decide prorrogar la MIPONUH hasta el 30 de noviembre de 1999. Una vez más, el Consejo de Seguridad a través de la Resolución 1277 $(1999)^{90}$, decidió mantener en funciones la MIPONUH a fin de garantizar una transición por etapas, que culminaría el 15 de marzo de 2000, a una futura Misión Civil Internacional de Apoyo a Haití (MICAH).

La tarea principal encargada a la MIPONUH era la de ofrecer asistencia al Gobierno de Haití en la profesionalización de la Policía Nacional de Haití. La MIPONUH, otorgó especial atención a la asistencia a nivel de supervisores y en la formación de unidades especializadas de policía. Otras tareas incluían vigilar la actuación de la policía, orientar a los oficiales de policía en cuanto a sus obligaciones diarias y mantener una estrecha coordinación con los asesores técnicos de la PNH subvencionados por el PNUD y los donantes bilaterales ${ }^{91}$.

86 S/RES/1141 (1997), Consejo de Seguridad, 3837ª sesión, 28 de noviembre de 1997.

87 S/RES/1141 (1997), op. cit., párrafo 2 y 7; S/1997/832/Add.1, op. cit., párrafo 2.

88 Previamente, en fecha 22 de octubre de 1998, el Presidente de la República de Haití había solicitado por carta dirigida al secretario general a las Naciones Unidas que «tengan a bien seguir cooperando con Haití con miras al fortalecimiento de la policía. La forma que ha de revestir esa cooperación y los medios que hayan de utilizarse podrán ser objeto de discusiones entre las instancias especializadas de las Naciones Unidas y de Haití.»

S/1998/1003, Anexo, Carta de fecha 27 de octubre de 1998 dirigida al Secretario General por el representante permanente de Haití ante las Naciones Unidas.

S/1998/1064, Informe del Secretario General sobre la Misión de la Policía Civil de las Naciones Unidas en Haití, 11 de noviembre de 1998, párrafo 32.

89 S/RES/1212 (1998), Consejo de Seguridad, 3949ª sesión, 25 de noviembre de 1998.

90 S/RES/1277 (1999), Consejo de Seguridad, 4074ª sesión, 30 de noviembre de 1999.

91 Establecido en la Resolución 1141 (1997), su tarea era «según los arreglos descritos en los párrafos 39 y 40 del informe del Secretario General de 31 de octubre de 1997 y en los párrafos 2 a 
A pesar de que se fueron cumpliendo los objetivos marcados, la dificultad para la organización y cumplimiento del organigrama previsto de cara a la celebración de las elecciones legislativas y municipales previstas para el 19 de marzo de 2000 y la falta de consolidación de las instituciones democráticas fueron los principales escollos a los que se tuvo que enfrentar esta misión. Durante el tiempo que duró lo misma, se produjeron reuniones de coordinación entre la MIPONUH y la MICIVIH para armonizar sus respectivas actividades y preparar la transición a la Misión Civil Internacional de Apoyo en Haití (MICAH) ${ }^{92}$.

f) La Misión Civil Internacional de Apoyo en Haití: MICAH (marzo 2000-febrero de 2001)

El 16 de marzo de 2000, la Misión Civil Internacional de Apoyo en Haití (MICAH) sustituyó a la MINOPUH. La Asamblea General, en su Resolución $54 / 193^{93}$ de fecha 17 de diciembre de 1999, decidió establecer la MICAH con el fin de consolidar los resultados conseguidos por la Misión Civil Internacional en Haití, la Misión de Policía Civil de las Naciones Unidas en Haití y misiones anteriores de las Naciones Unidas. Las tres esferas de actividad de la misión eran justicia, derechos humanos y policía. Asimismo, se determinó que la Misión debía durar hasta el 6 de febrero de 2000 y que se transferirían a esta el personal y las propiedades de la Misión Civil Internacional en Haití y la Misión de Policía Civil de las Naciones Unidas en Haití.

Tal y como reconoció el propio Secretario General de las Naciones Unidas en su Informe sobre la Misión Civil Internacional de Apoyo en Haití, de fecha 19 de abril de 2001, la MICAH se creó inicialmente con un mandato

12 de la adición de ese informe incluida la supervisión de la actuación de la Policía Nacional de Haití sobre el terreno».

S/1997/832, Informe del Secretario general sobre la Misión de Transición de las Naciones Unidas en Haití, 31 de octubre de 1997, párrafos 39 y 40.

S/1997/832/Add.1, Informe del Secretario General sobre la misión de las Naciones Unidas para la transición en Haití, párrafos 2 a 12.

92 La información reflejada se ha obtenido del Informe del Secretario General sobre la Misión de Policía Civil de las Naciones Unidas con fecha de 25 de febrero de 2000 (S/2000/150) y de Declaración del Presidente del Consejo de Seguridad sobre Haití con fecha de 15 de marzo de 2000 (S/PRST/2000/8).

S/2000/150, Informe del Secretario General sobre la Misión de Policía Civil de las Naciones Unidas en Haití, 25 de febrero de 2000.

S/PRST/2000/8, Declaración del Presidente del Consejo de Seguridad, 15 de marzo de 2000.

93 A/RES/54/193, Asamblea General, 18 de febrero de 2000. 
de 11 meses, de los que tres se perdieron debido al retraso de las contribuciones voluntarias necesarias. Esta demora se prolongó como consecuencia de la lentitud de los procedimientos de contratación de asesores, la mayoría de los cuales no ocuparon sus puestos hasta agosto de 2000. Se puede decir que esta misión no cumplió con sus expectativas y si tildarla de fracaso es un término un poco duro, desde luego no se lograron los objetivos pretendidos. El Secretario General, y cito textualmente, dijo respecto de la MICAH:

«La ejecución de la mayoría de los programas de la MICAH se concentraron en apena unos meses y que la Misión nunca se desarrolló completamente... La brevedad del período de trabajo limitó la eficacia global de la $\mathrm{MICAH} \gg^{94}$.

Su mandato ${ }^{95}$ fue el de consolidar los resultados conseguidos por la MINOPUH y misiones anteriores de las Naciones Unidas en Haití, así como por la MICIVIH, que era una labor conjunta de las Naciones Unidas y la Organización de los Estados Americanos (OEA) para fomentar el respeto por los derechos humanos en Haití. La misión tenía como objetivo seguir fomentando los derechos humanos y fortalecer la efectividad de la policía y el sistema judicial de Haití, así como coordinar y facilitar el diálogo de la comunidad internacional con los agentes políticos y sociales de Haití.

Durante el año que duró la misión se consiguió consolidar la estructura de la $\mathrm{PNH}$, sin embargo, ante la falta de colaboración de las autoridades haitianas la inseguridad pública aumentó y los donantes bilaterales optaron por dejar de proporcionar la ayuda directamente al gobierno haitiano y la canalizaron a través de ONG. Fue la Resolución del Consejo de Seguridad 1277 (1999), la que estableció que el mandato de la MIPONUH finalizaba el 15 de marzo de $2000^{96}$.

g) El apoyo unánime al despliegue de una Fuerza Multinacional Interina en el año 2004

El 5 febrero de 2004, estalló una rebelión armada en la ciudad de Gonaives que se propagó rápidamente a lo largo del país. Ante la incapacidad del aparato del Estado para hacer frente a la insurrección, las tropas rebeldes fue-

94 A/55/905, Informe del Secretario General sobre la Misión Civil Internacional de Apoyo a Haití, 19 de abril de 2001.

95 A/RES/54/193, op. cit.

96 S/RES/1277 (1999), op. cit., párrafo 1. 
ron cercando la capital de la República. A pesar de los intentos de mediación por parte de la comunidad internacional, la oposición a Aristide amenazó con entrar en Puerto Príncipe, lo que provocó la salida del Presidente.

El 26 de febrero de 2004, ante la situación de conflicto interno que había estallado en Haití, el Consejo de Seguridad emitió la Declaración S/ PRST/2004/4, en la cual expresó su profunda preocupación por el deterioro de la situación política, humanitaria y de seguridad en Haitíi ${ }^{97}$. Esta Declaración dejó la puerta abierta a la posibilidad de intervenir militarmente en el país al establecer que consideraría con carácter urgente y de conformidad con la Carta de las Naciones Unidas, «las opciones de actuación internacional, incluida la de una fuerza internacional en apoyo de un arreglo político, de conformidad con la Carta de las Naciones Unidas ${ }^{98}$. Unos días más tarde, el 29 de febrero de 2004 el Presidente Aristide abandonó el país, dando lectura a su carta de dimisión el Primer Ministro Yvonne Neptune ${ }^{99}$. Hay que decir que en los debates previos a la Resolución del Consejo de Seguridad que autorizó despliegue llevado a cabo en el año 2004 no existen opiniones en contra, ni siquiera por parte de aquellas naciones que intervinieron sin derecho a voto, tal y como había ocurrido en el año 1994, aprobándose unánimemente la Resolución 1529 (2004) por la cual se autorizaba el despliegue de una fuerza multinacional ${ }^{100} \mathrm{y}$ se subraya la necesidad de establecer unas condiciones adecuadas para el respeto de los derechos humanos ${ }^{101}$. Poco después de la renuncia de Aristide, el Presidente de la Corte Suprema de Haití, Boniface Alexandre, juraba su cargo como Presidente interino del país ${ }^{102}$.

La Resolución del Consejo de Seguridad 1529 (2004), de 29 de febrero de 2004, tras declarar que la situación de Haití constituía una amenaza para la

97 Bermejo García, R. y LópeZ-Jacoiste DíAz, E., «De la intervención por causas humanitarias a la responsabilidad de proteger. Fundamentos, similitudes y diferencias», Cuadernos de estrategia, $\mathrm{n}^{\circ}$ 160, Ministerio de Defensa, Instituto Español de Estudios Estratégicos, 2013, pp. 18-76

Autores como Bermejo García y Lopez-Jacoiste Díaz, sostienen que «la protección de los derechos humanos fundamentales ha ido escapando del ámbito de acción del principio de no intervención, recogido en el artículo 2, párrafo 7 de la Carta de las Naciones Unidas».

98 S/PRST/2004/4, Declaración del Presidente del Consejo de Seguridad, 4917ª sesión del Consejo de Seguridad celebrada el 26 de febrero de 2004.

99 S/2004/164, Consejo de Seguridad, Proyecto de Resolución, 29 de febrero de 2004.

100 S/PV.4919, Consejo de Seguridad, 4919 a sesión, 29 de febrero de 2004, Nueva York; S/ RES/1529 (2004), op. cit., párrafo 2.

101 LÓPEZ-JACOISTE DíAZ, E., «La responsabilidad de proteger: reflexiones sobre sus fundamentos y articulación», Anuario de Derecho Internacional, no 22 (2006), pp. 285-315

102 S/2004/300, Informe del secretario General sobre Haití, 16 de abril de 2004. 
paz y la seguridad internacionales ${ }^{103}$, así como para la estabilidad del Caribe, autorizó el despliegue de una Fuerza Multinacional Provisional (FMP) ${ }^{104}$, bajo mandato de los Estados Unidos de América, por un periodo máximo de tres meses ${ }^{105}$. Esta Resolución autorizaba la adopción de todas las medidas que fueran necesarias para el cumplimiento de su mandato. Entre las funciones de la Fuerza Multinacional estaba el ayudar al restablecimiento del orden, facilitar la distribución de asistencia humanitaria a quienes más la necesitaran, así como asistir a la policía y a la guardia costera haitianas a mantener el imperio de la ley y a proteger los derechos humanos en ese país ${ }^{106}$.

En este plazo de tres meses, el Presidente Interino Boniface Alexandre, tenía que organizar unas elecciones libres y democráticas, cosa que resultó imposible. La FMP se desplegó en base a criterios geográficos e intervinieron fuerzas armadas de los Estados Unidos de América, Francia, Canadá y Chile bajo el nombre «Operación Mañana Seguro» ${ }^{107}$. Previamente, el Representante Permanente de Haití en las Naciones Unidas ${ }^{108}$, presentó la solicitud de asistencia del Presidente interino del país, en el que este autorizaba la entrada de tropas en el país ${ }^{109}$. También declaró su disposición a establecer una fuerza de estabilización y seguimiento de las Naciones Unidas destinada a apoyar la continuación del proceso político pacífico y constitucional y a mantener un entorno seguro y estable, abriendo de este modo la puerta al despliege de una Misión internacional en el país bajo mandato de la ONU.

Finalmente, tras la visita de la misión de evaluación multidisciplinaria al país en marzo de $2004^{110}$ encabezada por Hocine Medili, el Consejo de Seguridad recomendó el establecimiento de la Misión de Estabilización de las Naciones Unidas en Haití (MINUSTAH).

\footnotetext{
103 Gutiérrez Espada, C., El «uso de la fuerza» en los Informes del Grupo de Alto Nivel (2004), del Secretario General (2005) y, a la postre, en el documento final de la cumbre de Fefes de Estado y de Gobierno, Anuario español de Derecho Internacional, $n^{\circ} 21$ (2005).

104 Centro de Noticias de la ONU, «Consejo de Seguridad autoriza fuerza multinacional interina para Haití», Nota de prensa de fecha 1 de marzo de 2004. Disponible en <www.un.org/ spanish/News/story.asp?NewsID=1930\#.UzATrKh5OHM>.

105 García Magariño, S., «Un análisis de las resoluciones del Consejo de Seguridad de la ONU ante el principio de la responsabilidad de proteger», Dilemata, número 13, 2013, pp. 93-119.

106 S/RES/1529 (2004), op. cit.

107 PIKE, J., «Operation secure tomorrow», en <globalsecurity.org>, 2011.

108 S/PV.4917, S/PV.4917, Acta de la 4917ª sesión del Consejo de Seguridad, 26 de febrero de 2004, p. 6.

109 S/2004/300, Informe del Secretario General sobre Haití, 16 de abril de 2004.

${ }_{110} \mathrm{~S} / 2004 / 300$, op. cit.
} 


\section{LA MISIÓN DE ESTABILIZACIÓN DE LAS NACIONES UNIDAS EN HAITÍ: MINUSTAH (2004-2016)}

La presencia continuada de fuerzas y cuerpos de seguridad multinacionales en el componente de la MINUSTAH permitió realizar una transición política pacífica y democrática. Partiendo de una situación de conflicto civil caracterizado por la ausencia de estructuras de Estado se logró convergir en un gobierno democrático surgido de unas elecciones libres y transparentes de acuerdo con los estándares internacionales. El sistema de estabilización diseñado por las Naciones Unidas para el país ha logrado un hito en la historia de Haití. Por primera vez en sus más de doscientos años de independencia, en el año 2010 se logró llevar a cabo una alternancia política pacífica en la jefatura del Estado mediante el traspaso de poder de un Presidente elegido democráticamente a otro de la oposición surgido de una contienda electoral democrática avalada por la comunidad internacional.

\section{a) La contribución del contingente de Naciones Unidas a la consolidación de la democracia en el país}

LaMisión de Estabilización de las Naciones Unidas en Haití(MINUSTAH) ${ }^{111}$ se estableció el 1 de junio de 2004 a través de la Resolución 1542 (2004) ${ }^{112}$ del Consejo de Seguridad, de fecha 30 de abril de 2004, en base a que los obstáculos para la estabilidad política social y económica seguían constituyendo una amenaza a la paz y a la seguridad internacionales de la región, lo que dio pie a actuar en virtud del capítulo vII de la Carta de las Naciones Unidas.

La Misión, estaba autorizada a incorporar un contingente hasta 6.700 efectivos militares y 1.622 policías civiles ${ }^{113}$. Además se incorporaron a la mis$\mathrm{ma}$, cerca de 550 funcionarios civiles internacionales, 150 voluntarios de las

\footnotetext{
${ }^{111}$ Información proporcionada por la Sección de Paz y Seguridad del Departamento de Información Pública en cooperación con el Departamento de Operaciones de Mantenimiento de la Paz. Disponible en <www.un.org/es/peacekeeping/missions/minustah/>.

FundaCión PARA LAS RELACIONES INTERNACIONALES Y EL DiÁLOGO EXTERIOR-FRIDE, Informe de Conferencia, Nueva York, 28 de enero de 2008. Disponible en <www.fride.org/descarga/ CR04_Haiti_seminario_ESP_abr08.pdf>.

112 S/RES/1542 (2004), Consejo de Seguridad, 4961ª Sesión, 30 de abril de 2004.

113 BISBAL, Pons. F., «Operación MINUSTAH en Haiti», Revista Atenea Seguridad y Defensa, $\mathrm{n}^{\circ} 10$ (2014), pp. 52-60.
} 
Naciones Unidas y 1.000 miembros del personal civil local ${ }^{114}$. Como veremos más adelante, en estos más de diez años trascurridos desde que desembarcó la MINUSTAH en el país, el contingente y el mandato de la Misión se han ido adaptando a las circunstancias. Bajo supervisión de la ONU, en el año 2006, se celebraron elecciones nacionales libres e imparciales ${ }^{115}$. El Consejo de las $\mathrm{Na}$ ciones Unidas, en la Resolución 1658 (2006) de fecha 14 de febrero, felicitaba al pueblo de Haití «por haber celebrado satisfactoriamente la primera ronda de las elecciones» ${ }^{116}$ en fecha 7 de febrero de ese año.

Desgraciadamente, cuando los indicadores económicos y sociales empezaban a dejar vislumbrar una cierta mejora en la situación de Haití, un terremoto de magnitud 7 en la escala de Richter sacudió el país. Era el 12 de enero de 2010. Hubo que lamentar la pérdida de más de 200.000 personas $^{117}$, entre ellas 102 funcionarios de las Naciones Unidas, entre los que se encontraban el Representante Especial, Sr. Hédi Annabi, el Representante Especial Adjunto, Sr. Luiz Carlos da Costa, el Comisionado de Policía interino, Sr. Douglas Coates, el Director de Asuntos Políticos, Sr. Gerard Le Chevallier, el Jefe de la Dependencia de Elecciones, Sr. Marc Plum, y otros miembros del personal militar, civil y de policía. Asimismo, hubo miles de heridos y más de un millón de desplazados. El terremoto destruyó Puerto Príncipe y supuso un duro golpe para la economía, la gobernabilidad y las infraestructuras del país. Según el gobierno haitiano, un tercio de los cerca de 60.000 funcionarios públicos perdieron la vida. Esta desgracia contribuyó a aumentar el clima de incertidumbre política que ha caracterizado a este país a lo largo de su historia, interrumpiendo un periodo de relativo progreso hacia la celebración de elecciones municipales, legislativas y presidenciales, que estaban programadas para febrero de 2010.

A la luz de las gravísimas consecuencias del terremoto sobre la capacidad del Estado haitiano, el Consejo de Seguridad, en su Resolución 1908 (2010) ${ }^{118}$, de 19 de enero, apoyó la recomendación del Secretario General de aumentar la dotación general de la MINUSTAH con 2.000 soldados y 1.500 policías

\footnotetext{
114 S/RES/1542 (2004), op. cit.

115 S/2006/592, Informe del Secretario General sobre la Misión de Estabilización de las Naciones Unidas en Haití, 28 de julio de 2006.

116 S/RES/1658 (2006), Consejo de Seguridad, 5372a sesión, 14 de febrero de 2006.

117 S/2010/200, Informe del Secretario General sobre la Misión de Estabilización de las Naciones Unidas en Haití, 22 de abril de 2010.

118 S/RES/1908 (2010), Consejo de Seguridad, 6261ª sesión, 19 de enero de 2010.
} 
adicionales, para ayudar en las tareas inmediatas de recuperación, reconstrucción y estabilidad en el país.

En el informe S/2010/200 ${ }^{119}$, de fecha 22 de abril de 2010, sobre la Misión de Estabilización de las Naciones Unidas en Haití, el Secretario General incluyó recomendaciones sobre el futuro papel de MINUSTAH. Estas recomendaciones habían sido aprobadas previamente por el Grupo Integrado de Planificación Estratégica de las Naciones Unidas y Haití el 7 de abril de 2010 en Puerto Príncipe. Se estableció que la Misión ayudaría al Gobierno a preservar los avances logrados hasta la fecha en materia de estabilización y facilitaría una transición sin tropiezos a una reconstrucción a largo plazo. También se constataba que gran parte de esa intensificación se podría lograr ampliando las actividades dentro del mandato actual, mientras que en algunas esferas la Misión debería prestar mayor asistencia técnica, operacional y logística al Gobierno y las instituciones estatales.

El Consejo de Seguridad, en su Resolución 1927 (2010) ${ }^{120}$, de 4 de junio de 2010, autorizó el despliegue temporal de 680 agentes de policía adicionales con el objetivo de reforzar la capacidad de la PNH. Además, la Resolución se hacía eco que la potestad y la responsabilidad primordial con respecto a la estabilización y el desarrollo correspondían al Gobierno y al pueblo de Haití, reconociendo el papel de apoyo de la MINUSTAH al respecto. El Consejo de Seguridad también reconocía la necesidad de que la MINUSTAH ayudara al Gobierno de Haití a proporcionar una protección adecuada a la población, prestando particular atención a las necesidades de los desplazados internos y otros grupos vulnerables, especialmente las mujeres y los niños. Pedía asimismo la continuidad de su colaboración con la Oficina de Coordinación de Asuntos Humanitarios (OCAH) y con el equipo de las Naciones Unidas en el país para apoyar la labor humanitaria y las tareas de recuperación.

Además, el Consejo solicitaba a la MINUSTAH que siguiera prestando al Gobierno de Haití y al Consejo Electoral Provisional el apoyo que estos solicitaran para los preparativos y la celebración de las elecciones y que, en cooperación con otros interesados internacionales, como la Organización de los Estados Americanos, coordinaran la asistencia electoral internacional. De

\footnotetext{
119 S/2010/200, Informe del Secretario General sobre la Misión de Estabilización de las Naciones Unidas en Haití, 22 de abril de 2010.

120 S/RES/1927 (2010), Consejo de Seguridad, 6330ª sesión, 4 de junio de 2010.
} 
este modo, en virtud del mandato del Consejo de Seguridad, la MINUSTAH apoyó al Gobierno en las elecciones presidenciales y legislativas, prestando asistencia técnica, logística y administrativa, y manteniendo la seguridad permanente.

El resultado de las elecciones proclamó vencedor al cantante Michel Martelly en la segunda vuelta, que tuvo lugar el 20 de marzo de 2011. El Secretario General, Ban Ki-Moon, elogió las elecciones y al pueblo de Haití por dar tan importante paso hacia la consolidación de la democracia y en su informe S/2011/540 ${ }^{121}$, de 25 de agosto de 2011, el Sr Ban escribió: «Haití ha experimentado, por primera vez en su historia, una transferencia pacífica del poder de un presidente democráticamente electo a otro de la oposición», lo que nos permite calificar estas elecciones como un hito en la historia del país y una gran contribución de las Naciones Unidas en la consolidación de democracia haitiana ${ }^{122}$.

b) La adaptación de los mandatos de la Misión a los cambios de realidades producidos en el transcurso del tiempo sobre el terreno

Tras más de un decenio sobre el terreno, las circunstancias a las que se ha tenido que enfrentar la Misión a lo largo del tiempo han evolucionado. En este sentido, el sistema de las Naciones Unidas, a través del Consejo de Seguridad, ha tenido que adaptar los mandatos de la MINUSTAH a estas modificaciones.

Actualmente, la función principal de la MINUSTAH se centra en el diálogo político y elecciones, aumento de la autoridad del Estado y refuerzo de sus capacidades, apoyo institucional, seguridad pública, apoyo a la reforma del estado de derecho y derechos humanos ${ }^{123}$. Hasta llegar a estas prioridades de actuación, el Consejo ha variado en múltiples ocasiones los fines de las

${ }^{121}$ S/2011/540, Informe del Secretario General sobre la Misión de Estabilización de las Naciones Unidas en Haití, 25 de agosto de 2011.

122 Hemos de precisar que durante el periodo electoral se produjeron denuncias de intervención política hacia la Misión de Monitoreo Electoral de la OEA en Haití.

Johnston, J. y Weisbrot, M., «Las elecciones fracasadas de Haití», Centro de Investigación en Economía y Política, febrero 2011; RosNicK, D., «La Organización de Estados Americanos en Haití: ¿Monitoreo electoral o intervención política?», Center for Economic and Policy Research, Washington, 2011, p 12.

${ }^{123}$ Se puede consultar información relativa al mismo en francés en <www.minustah.org/la-mission/ mandat-de-la-minustah/>. Asimismo en el anexo referente a las Misiones se ha reflejar pormenorizadamente los ámbitos de actuación con sus correspondientes funciones. 
operaciones y su dotación, para adaptarlos a las circunstancias cambiantes y a las nuevas necesidades impuestas por la situación política, de seguridad y socioeconómica del país.

En el año 2004, a raíz del desembarco de la MINUSTAH en Haití, el mandato inicial de la Misión se estableció en la ya mencionada Resolución 1542 (2004). En este primer momento se propuso un mandato de carácter general consistente esencialmente en llevar a cabo una actuación integral que permitiera actuar tanto en el ámbito de la seguridad como en el establecimiento de las bases para un desarrollo a largo plazo ${ }^{124}$.

Un año después, en 2005, mediante la Resolución 1608 (2005) ${ }^{125}$ el Consejo solicitó a la MINUSTAH que concentrara la utilización de sus recursos, incluidos los de policía civil, en aumentar la seguridad y la protección en el período electoral, lo que incluía una revisión del mandato de cada uno de los oficiales de policía civil. Asimismo, se hizo hincapié en la necesidad de que se llevara a cabo una coordinación efectiva con las autoridades de Haití para que tanto la policía civil de la MINUSTAH como la PNH orientaran sus esfuerzos en la misma dirección. El Consejo de Seguridad consideró oportuno dotar a la MINUSTAH de las funciones necesarias para investigar y certificar al personal nuevo de la PNH. Por otro lado, solicitó a MINUSTAH que aumentara su capacidad para ejecutar proyectos de efecto rápido e instó a que se estrechara la coordinación entre las diversas entidades de desarrollo en Haití para lograr una mayor eficiencia en la labor de desarrollo.

En el ámbito de los derechos humanos, el Consejo de Seguridad requirió a la MINUSTAH la puesta en funcionamiento a la mayor brevedad posible de la Brigada Conjunta de Investigaciones Especiales, cuerpo que tenía como misión apoyar la labor de investigación en los casos de violaciones de los derechos humanos, especialmente en aquellos en los que se mediara denuncia por

124 S/RES/1542 (2004), op. cit., párrafo VII.

En este sentido, las principales tareas enunciadas consistían en ayudar al Gobierno de transición a establecer un entorno seguro y estable, la supervisión, reestructuración y reforma de la PNH, la prestación de asistencia mediante programas integrales y a largo plazo de desarme, desmovilización y reinserción, asistir en el restablecimiento y mantenimiento del estado de derecho, la seguridad pública y el orden público, proteger al personal de las Naciones Unidas, los servicios, las instalaciones y el equipo y a los civiles que se encontraran en riesgo inminente de violencia física, apoyar el proceso político y constitucional, ayudar en la tarea de organizar, supervisar y llevar a cabo elecciones municipales, parlamentarias y presidenciales libres y limpias, apoyar al Gobierno de transición y a las instituciones y organizaciones haitianas en sus esfuerzos por promover y proteger los derechos humanos; e informar sobre la situación de los derechos humanos en el país.

125 S/RES/1608 (2005), Consejo de Seguridad, 5210a sesión, 22 de junio de 2005. 
la participación de la PNH. Como novedad, con esta Resolución las Naciones Unidas deciden llevar a cabo una labor pedagógica respecto de la Misión al establecer una estrategia de comunicación enfocada a que la población de Haití entendiera mejor su mandato y su función.

Por su parte, en la Resolución 1702 (2006) ${ }^{126}$, de fecha 15 de agosto, el Consejo introdujo un nuevo componente en el mandato de la Misión al solicitarle expresamente a la MINUSTAH que orientara sus esfuerzos en el ámbito de la promoción del diálogo y la reconciliación nacional. Se produjo de este modo una reorientación de sus trabajos de desarme, desmovilización y reintegración mediante la ejecución de un programa comunitario amplio de reducción de la violencia adaptada a las condiciones locales. Este programa se enfocó principalmente a asistir a las iniciativas que se produjeran en el ámbito del fortalecimiento de la gobernanza local y el Estado de derecho, promoviendo las oportunidades de empleo a ex integrantes de bandas armadas y a jóvenes en situación de riesgo. Conforme se fueron alcanzando los objetivos de pacificación, seguridad y estabilización, el Consejo amplió el ámbito de actuaciones a otros sectores. Este fue el caso del Servicio de Guardacostas de Haití o el apoyo a las administraciones judicial y penitenciaria.

En el año 2007, gracias a las Resoluciones 1743 y 1780 (2007) ${ }^{127}$, el Consejo amplió una vez más las responsabilidades de la MINUSTAH al encargarle que apoyara los esfuerzos del Gobierno en relación con la estabilización y buena gobernanza del país. Del mismo modo, se empezó a tomar consciencia de la necesidad de coordinarse con otros actores así como que la presencia de las Naciones Unidas en el país fuera acompañada de una mejora de las condiciones de vida de la población. Durante este año 2007, se introdujo la gestión de fronteras en la agenda del Consejo, lo que implicó llevar a cabo un programa de capacitación ad hoc. También deciden reafirmar el mandato de la MINUSTAH en materia de derechos humanos y exhorta a las autoridades de Haití a que sigan procurando la promoción y la protección de los derechos humanos.

Ante la oportunidad que se abrió gracias al proceso político que estaba teniendo lugar en Haití, el Consejo, a través de la Resolución 1840 (2008) ${ }^{128}$, de fecha 14 de octubre, consideró oportuno mostrar su apoyo expreso a través de la MINUSTAH. Así, en cooperación con el Gobierno de Haití, se encargó

\footnotetext{
126 S/RES/1702 (2006), Consejo de Seguridad, 5513a sesión, 15 de agosto de 2006.

127 S/RES/1743 (2007), Consejo de Seguridad, $5631^{\text {a }}$ sesión, 15 de febrero de 2007; S/RES/1780 (2007), Consejo de Seguridad, 5758 a sesión, 15 de octubre de 2007.

128 S/RES/1840 (2008), Consejo de Seguridad, 5993ª sesión, 14 de octubre de 2008.
} 
que se llevara a cabo un diálogo político inclusivo y de reconciliación nacional, prestando asistencia logística y de seguridad en el proceso electoral.

La Resolución 1892 (2009) del Consejo de Seguridad encomendó nuevas tareas a la MINUSTAH ${ }^{129}$, tendentes a apoyar el proceso político en el país, promover un diálogo político y de reconciliación nacional y prestar asistencia logística y de seguridad de cara a la celebración de las elecciones previstas para el año siguiente.

Tras el devastador terremoto que azotó a Haití el 12 de enero de $2010^{130}$, el Consejo de Seguridad, a través de las Resoluciones 1908 y 1927 (2010) aumentó la dotación general de la MINUSTAH como apoyo en las tareas inmediatas de recuperación, reconstrucción y estabilidad, lo que constituyó una intervención humanitaria de carácter militar por catástrofes naturales. Asimismo, las Naciones Unidas encargaron a la MINUSTAH que siguiera cumpliendo su mandato y colaboración con la Oficina de Coordinación de Asuntos Humanitarios y con el equipo de las Naciones Unidas en el país, apoyando la labor humanitaria y de recuperación.

La MINUSTAH continuó aportando apoyo logístico y técnico al Gobierno de Haití con el fin de llevar a buen término sus operaciones, fomentar la capacidad de las instituciones del estado de derecho en el plano nacional y local, y acelerar la aplicación de la estrategia del Gobierno para la reubicación de los desplazados. A pesar de que, dada la situación la celebración de las elecciones en el plazo previsto se convirtió en una tarea titánica, el Consejo pidió a la MINUSTAH que siguiera prestando su apoyo al Gobierno de Haití y al Consejo Electoral Provisional en los preparativos y la hipotética celebración de las elecciones, así como que coordinara la asistencia electoral internacional en colaboración con otras instancias como la Organización de los Estados Americanos.

En otro orden de cosas, y al tratarse de una Misión tan sostenida en el tiempo, el Consejo de Seguridad ha ajustado hasta en nueve ocasiones el contingente de la Misión. Poco a poco, y conforme pasaron los años, se fue reduciendo el componente militar de la MINUSTAH y se le dio más importancia al componente de policía civil para de este modo reducir la presencia de

129 S/RES/1892 (2009), Consejo de Seguridad, 6200ª sesión, 13 de octubre de 2009.; S/RES/1780 (2007), op. cit.

130 Diario El País, «Un fuerte terremoto reduce a escombros la capital de Haití», artículo publicado el 13 de enero de 2010.

131 S/RES/1908 (2010), Consejo de Seguridad, 6261 sesión, 19 de enero de 2010; S/RES/1927 (2010), Consejo de Seguridad, 6330ª sesión, 4 de junio de 2010. 
fuerzas armadas en el país y establecer las bases necesarias para transferir las responsabilidades de seguridad a la $\mathrm{PNH}$.

Como ya hemos visto, el año 2010 se produjo un importante retroceso en cuanto a los avances logrados a raíz del terremoto que asoló el país. Este supuesto de fuerza mayor obligó a las Naciones Unidas a dar marcha atrás a su plan de retirada de las fuerzas armadas, viéndose obligada a aumentar el componente militar para poder hacer frente a las consecuencias de aquella tragedia y asegurar la seguridad en el país. Una vez más, con el transcurso de los años y una vez superado el terremoto se ha podido volver a disminuir la presencia de fuerzas militares extranjeras en el país y fortalecer nuevamente el componente de policía civil. El contingente de MINUSTAH fue objeto de cambios en su composición a raíz de las siguientes Resoluciones del Consejo de Seguridad ${ }^{132}$ : 1542 (2004), 1608 (2005), 1702 (2006), 1780 (2007), 1892 (2009), 1908 y 1927 (2010), 2012 (2011), 2070 (2012) y 2119 (2013).

A modo de recapitulación, en agosto de 2016, un total de 19 países aportaban tropas al contingente militar, mientras que 46 lo hacen a la policía civil, convirtiendo a esta Misión de las Naciones Unidas en una de las más internacionales de su historia ${ }^{133}$.

c) El componente de Derechos Humanos como eje de la Misión de Estabilización de las Naciones Unidas en Haití

La Sección de Derechos Humanos de la MINUSTAH, en adelante Sección, se constituyó el 30 de abril de 2004 como parte integrante de la Misión

132 S/RES/1542 (2004), op. cit., párrafo 4.

Esta Resolución estableció un máximo de 6.700 efectivos militares y un máximo de 1.622 miembros de la policía civil, incluidos los asesores y las unidades constituidas. Además la misión contó con 548 personal civil internacional, 154 voluntarios de las Naciones Unidas y 995 personal civil local.

S/RES/1608 (2005), Consejo de Seguridad, 5210ª sesión, 22 de junio de 2005; S/RES/1702 (2006), el Consejo de Seguridad, $5513^{\text {a }}$ sesión, 15 de agosto de 2006; S/RES/1780 (2007), Consejo de Seguridad, $5758^{a}$ sesión, 15 de octubre de 2007; S/RES/1892 (2009), Consejo de Seguridad, $6200^{a}$ sesión, 13 de octubre de 2009; S/RES/1908 (2010), Consejo de Seguridad, $6261^{\text {a }}$ sesión, 19 de enero de 2010; S/RES/1927 (2010), Consejo de Seguridad, 6330ª sesión, 4 de junio de 2010; S/RES/2012 (2011), Consejo de Seguridad, 6631 a sesión, 14 de octubre de 2011; S/RES/2070 (2012), Consejo de Seguridad, 6845 a sesión, 12 de octubre de 2012; S/RES/2119 (2013), Consejo de Seguridad, 7040ª sesión, 10 de octubre de 2013. La Resolución 2119 (2013) redujo el contingente militar de MINUSTAH hasta dejarlo en 5.021 efectivos militares y mantuvo el de policía en 2.601 agentes.

133 S/2016/753, op. cit., pp. 20-22. 
a través de la Resolución 1542 (2004) del Consejo de Seguridad ${ }^{134}$. El máximo responsable de esta Sección es, con el fin de poder llevar a cabo la mejor coordinación posible entre los organismos que componen el sistema de las Naciones Unidas, el representante de la Oficina del Alto Comisionado para los Derechos Humanos en Haití1 ${ }^{135}$.

El mandato de la MINUSTAH en el ámbito de los derechos humanos, consistía principalmente en apoyar al Gobierno de transición, a las instituciones y a los grupos haitianos de derechos humanos, en sus esfuerzos por promover y proteger estos derechos, centrándose especialmente en las mujeres y los niños. Además, la MINUSTAH cooperó con la Oficina del Alto Comisionado para los Derechos Humanos con el objetivo supervisar su situación en especial respecto de los refugiados y las personas que regresan.

Asimismo se instó a la MINUSTAH a prestar asesoramiento y asistencia en la investigación de las infracciones de los derechos humanos y del derecho internacional humanitario, en colaboración con la Oficina del Alto Comisionado para los Derechos Humanos, «con objeto de poner fin a la impunidad ${ }^{136}$. Este mandato, confirmado a lo largo del tiempo por las diferentes Resoluciones del Consejo de Seguridad ${ }^{137}$ relativas a las prórrogas de la Misión, ha sido asumido por la Sección a través de ocho oficinas regionales y cuatro locales sitas en Puerto Príncipe.

Es importante mencionar en este sentido la Resolución 2070 (2012) del Consejo de Seguridad, en la cual se consideró necesario reafirmar el mandato de la Misión en materia de derechos humanos, calificándolo como un «componente esencial ${ }^{138}$ de la misma. El Consejo de Seguridad va un paso más lejos al determinar que el respeto a los derechos humanos en Haití constituye un elemento imprescindible para la estabilidad del país, y por ende para poder llevar a cabo las actividades necesarias en cualquier ámbito de desa-

\footnotetext{
134 S/RES/1542 (2004), op. cit.; Oficina del Alto Comisionado para los Derechos Humanos, «OACDH en Haití (2006-2007)», Antecedentes, $O A C D H$, noviembre de 2014.

135 Haut-Commissariat des Nations Unies aux Droits de l'Homme/ Mission de StabiliSATION DES NATIONS Unies EN HaïTI, Rapport semestriel sur les droits de l'homme en Haïti, Juillet-Décembre 2012, abril 2013.

136 S/RES/1542 (2004), op. cit.

${ }^{137}$ Para un estudio pormenorizado de los cambios producidos en los mandatos de la Misión de las Naciones Unidas para la Estabilización de Haití desde el año 2004 hasta el 2013 se puede consultar el epígrafe correspondiente a esta Misión recogido en el capítulo anterior.

${ }^{138}$ S/RES/2070 (2012), Consejo de Seguridad, 6845ª sesión, 12 de octubre de 2012.
} 
rrollo. Las actividades de la Sección ${ }^{139}$ se llevan a cabo en base a tres pilares: los derechos humanos y la administración de justicia, los derechos humanos en el campo de las políticas públicas y del fortalecimiento de las capacidades y los derechos humanos en el campo de la protección humanitaria y el desarrollo. Entre sus acciones cabría destacar el establecimiento de un sistema de comunicación con las diferentes entidades nacionales gubernamentales y no gubernamentales que se ocupan de los derechos humanos en el país. Se ha priorizado el establecimiento de contactos y relaciones en el ámbito de la justicia y la seguridad ciudadana, la sociedad civil y la Oficina de Protección del Ciudadano (OPC). Tras años de Misión en el país y la mejora de las condiciones de seguridad, la Sección ha tratado de acercarse al ciudadano y a la sociedad para que no sea vista tanto como un órgano integrado en la maquinaria de los cuerpos y fuerzas de seguridad de las Naciones Unidas, sino como un organismo que favorece el desarrollo y el bienestar de la sociedad haitiana a través de la colaboración y el trabajo conjunto con sus entidades e instituciones ${ }^{140}$.

No podemos olvidar el papel primordial que ha jugado la Sección en el ámbito de la pacificación y creación de un entorno seguro en Haití. Hay que recordar que este organismo fue el encargado de apoyar y coordinar la puesta en marcha de un sistema común de seguridad creado por los cuerpos y fuerzas de seguridad de las Naciones Unidas, las Organizaciones No Gubernamentales y la PNH. Esta iniciativa ha permitido, a través de un plan de desarrollo estratégico, llevar a cabo una iniciativa común de mantenimiento del orden

${ }^{139}$ Información facilitada por la Misión de Estabilización de las Naciones Unidas en Haití. Disponible en <www.minustah.org/>.

140 Misión de las Naciones Unidas para la Estabilización de Haití, Actividades, Derechos Humanos. Información disponible en <www.minustah.org/activites/droits-de-lhomme/>. Para más profundización se puede consultar entre otros los siguientes informes: S/2004/908, Informe del Secretario General sobre la misión de estabilización de las Naciones Unidas en Haití, 18 de noviembre de 2004; S/2006/592, Informe del Secretario General sobre la Misión de Estabilización de las Naciones Unidas en Haití, 28 de julio de 2006; S/2008/586, Informe del Secretario General sobre la misión de estabilización de las Naciones Unidas en Haití, 27 de agosto de 2008; S/2010/200, Informe del Secretario General sobre la Misión de Estabilización de las Naciones Unidas en Haití, de 22 de abril de 2010; S/2011/540, Informe del Secretario General sobre la Misión de Estabilización de las Naciones Unidas en Haití, 25 de agosto de 2011; S/2012/678, Informe del Secretario General sobre la misión de estabilización de las Naciones Unidas en Haití, 31 de agosto de 2012; S/2013/493, Informe del Secretario General sobre la misión de estabilización de las Naciones Unidas en Haití, 19 de agosto de 2013; S/2014/617, Informe del Secretario General sobre la misión de estabilización de las Naciones Unidas en Haití, 29 de agosto de 2014 . 
y desplegar, tras el terremoto, agentes de policía en determinados campos de refugiados con el fin de proteger a sus moradores. Asimismo, la Sección ha llevado a cabo talleres de formación en el campo de los derechos humanos, en particular en lo referente a la violencia sexual y el género ${ }^{141}$.

La Comisión Interamericana de Derechos Humanos, en su informe del año 2008, reconoció los esfuerzos llevados a cabo por el país, aunque se mostraba preocupada por la violencia que se ejercía sobre los niños y las mujeres. En este sentido el referido informe aplaude dos iniciativas llevadas a cabo por el gobierno haitiano como son el «compromiso de expresado por el Gobierno de Haití de ratificar los tratados de derechos bumanos de los cuales Haití todavía no es parte» y el compromiso renovado para establecer «un comité inter-ministerial encargado de la coordinación de las comunicaciones entre el Gobierno de Haití y los órganos creados por los tratados de derechos humanos ${ }^{142}$. Asimismo se destaca la elaboración e implementación por parte del Ministerio de la Mujer de un plan de acción que incorporaba elementos de prevención, educación pública, reducción de la pobreza y protección para las mujeres.

En relación con este informe de la Comisión hay que hacer mención al muy crítico voto particular del Comisionado Freddy Gutiérrez Trejo, el cual califica la actuación de las Naciones Unidas en el país de deplorable a través de la MINUSTAH, a la que tilda de fuerza de ocupación. Además, unos párrafos más adelante da a entender que esta Misión ha llevado a cabo innumerables actos de barbarie y de violencia sistemática ${ }^{143}$. Hay que decir que en el informe al que hemos hecho referencia no consta ninguna otra denuncia a la actuación de la MINUSTAH en este sentido. De hecho, el informe anual de la Comisión del año 2009 alaba la actuación de la MINUSTAH a la que reconoce su compromiso en asegurar las condiciones de paz y de seguridad en el país desde el año $2004^{144}$.

\footnotetext{
141 Sección de Paz y Seguridad del Departamento de Información Pública, en cooperación con el Departamento de Operaciones de Mantenimiento de la Paz. Disponible en <www.un.org/ $\mathrm{fr} /$ peacekeeping/issues/humanrights.shtml>.

142 OEA/Ser.L/V/II.131, doc. 36, Comisión Interamericana de Derechos Humanos, Organización de los Estados Americanos, Observaciones de la CIDH sobre su visita a Haití en abril de 2007, 2 de marzo de 2008.

${ }^{143}$ OEA/Ser.L/V/II.131, doc. 36, op. cit., voto razonado de Comisionado Freddy Gutiérrez Trejo sobre informe Haití aprobado durante el 129 período extraordinario de sesiones de la CIDH en septiembre de 2007 (Asunción, Paraguay).

144 Comision Interamericana De Derechos Humanos, Informes, Informe anual de la Comisión Interamericana de Derechos Humanos 2009, cap. IV, Haití, párrafo 396.
} 
Si bien es cierto que el terremoto del año 2010 supuso un retroceso, los indicadores y diferentes informes demuestran que el hecho de que se haya producido una estabilidad en el ámbito de la seguridad ha permitido en gran medida normalizar la vida democrática, lo que ha redundado en una mejora generalizada de las condiciones de vida. Hasta este momento, los avances habían sido considerables, como así lo ponía de manifiesto el Sr. Michael Forst en su informe de mayo del año 2010.

«Es indispensable recordar que el país estaba encauzado en la vía del progreso y es importante reafirmar que el impulso que se venía dando al país desde hacía varios meses sólo ha quedado interrumpido, y no quebrado. Se habían realizado progresos notables en la esfera de los derechos civiles y políticos, pese a que aún quedaba mucho camino que recorrer hasta que el país tuviese un ordenamiento penal que respondiese a las exigencias del estado de derecho. La situación de la seguridad había mejorado, había disminuido el número de secuestros, los principales jefes de pandillas habían sido detenidos, todo ello constituía un cuadro en que podían divisarse señales alentadoras» ${ }^{145}$.

Tras el terremoto, la defensa y promoción de los derechos humanos volvieron a situarse en el epicentro de las iniciativas emprendidas en el país. Amnistía Internacional, en una declaración enviada al Secretario General de las Naciones Unidas nada más producirse el terremoto solicitaba a la Asamblea General de las Naciones Unidas situar a los derechos humanos en el epicentro de los esfuerzos a realizar para la asistencia y reconstrucción del país ${ }^{146}$. Por su parte, el Sr. Forst expresó su preocupación acerca de la desconexión entre las ONG haitianas y la Sección ${ }^{147}$ y achacó el problema al hecho de que esta Sección esté integrada en la Misión.

Desde septiembre de 2015, la MINUSTAH ha prestado apoyo a la Office de la Protection du Citoyen, equivalente al defensor del pueblo español, a

145 A/HRC/14/44, Consejo de Derechos Humanos, Asamblea General, Informe del Experto independiente sobre la situación de los derechos humanos en Haití, Michel Forst, 3 de mayo de 2010.

146 A/HRC/S-13/NGO/1, Consejo de Derechos Humanos, Asamblea General, Written statement submitted by Amnesty International, a non-governmental organization in special consultative status, 26 de enero de 2010.

147 A/HRC/17/42, Consejo de Derechos Humanos, Asamblea General, Informe del Experto independiente sobre la situación de los derechos humanos en Haití, Michel Forst, 4 de abril de 2011. 
través de la adscripción de un experto internacional cuya labor consiste fundamentalmente en colaborar en la elaboración del plan estratégico que debe abarcar el periodo comprendido entre 2016 y $2019^{148}$.

\section{d) La implicación de las Fuerzas Armadas españolas en el contingente de la MINUSTAH}

El 2 de julio de 2004, el Consejo de Ministros del Gobierno español acordó destacar una misión humanitaria a Haití149. Por su lado, el Presidente del Gobierno, compareció el 6 de julio ante el Pleno del Congreso de los Diputados $^{150}$ para solicitar su aprobación. En la citada comparecencia informó de dicha participación, sometiéndola a votación. El resultado fue de 309 votos emitidos, todos ellos a favor. El 10 de septiembre de $2004^{151}$ el Consejo de Ministros aprobó la participación del Reino de España en la Misión de Estabilización de las Naciones Unidas en Haití (MINUSTAH) ${ }^{152}$.

España participó en esta misión bajo la denominación de FIMEX-H $\mathrm{H}^{153}$, con la Unidad de la Brigada de Infantería de Marina. El núcleo principal lo conformó el Batallón Hispano-Marroquí bajo dirección española. El FIMEX-H, recibió del Jefe de Estado Mayor de Defensa (JEMAD) el mandato de «integrarse en las Fuerzas de las Naciones Unidas para la Estabilización de Haití, para contribuir a mejorar la seguridad y facilitar la asistencia humanitaria» ${ }^{154}$. Los primeros militares españoles, unos 200 hombres y mujeres desembarcaron en Cap Haitien el 30 de octubre de 2004, tras haber realizado la travesía del océano atlántico a bordo del Buque de Asalto Anfibio «Castilla». La base de la unidad se estableció en Fort Liberté, población situada en la costa noroeste de Haití, fundando la Base Miguel de Cervantes. Esta población era relativamente tranquila y contaba con la presencia de la $\mathrm{PNH}$ y la rama civil de la MINUSTAH.

\footnotetext{
148 S/2016/225, op. cit., párrafo 21; S/2016/753, op. cit., párrafo 14.

149 Consejo de Ministros, Rueda de Prensa, 2 de julio de 2004.

150 Congreso de los Diputados, Boletín Oficial de las Cortes Generales, nº 49, 6 de julio de 2004, p. 11 y 12.

151 Consejo de Ministros, Rueda de Prensa, 10 de septiembre de 2004.

152 Como base de este epígrafe se ha obtenido la información del libro «El conflicto de Haití», publicado por el Ministerio de Defensa en el año 2011. GonzÁlez Hernández, M. y Manero Salvador, A., El Conflicto de Haití, Ministerio de Defensa, Madrid, 2011, pp. 170-194.

${ }^{153}$ Fuerza Expedicionaria de Infantería de Marina en Haití.

154 GonZález HernándeZ, M. y Manero Salvador, A., op. cit., p. 122.
} 
Entre los principales problemas a los que tuvieron que hacer frente se encontraban la asistencia humanitaria y las actuaciones contra bandas armadas. Dada la proximidad del paso fronterizo con la República Dominicana de Ouanaminthe ${ }^{155}$ y Fort Liberté, y el foco de problemas en el que se convertía los días de mercado ${ }^{156}$, se decidió establecer un destacamento en este lugar durante 18 meses. El incidente más destacado se produjo el 12 de enero de $2006^{157}$ cuando una turba atacó al destacamento hispano-marroquí y lanzó cocteles molotov contra la sede del mismo. El incidente se saldó con dos haitianos muertos consecuencia de los disparos realizados por las fuerzas de seguridad haitianas. En febrero de 2006 se celebraron elecciones presidenciales. Las principales dificultades detectadas por la FIMEX-H fueron la ausencia de carnet de identidad y de un censo fiable, la falta de infraestructuras y la inseguridad de las aldeas remotas. La organización del proceso electoral fue llevada a cabo por el Departamental Joint Electoral Security CenterDJESC, el cual estaba compuesto por representantes civiles y militares de las Naciones Unidas, la OEA, la PNH, la policía de Naciones Unidas (UNPOL) y observadores internacionales. Las tropas españolas enviaron a sus representantes permanentes cuando fueron requeridos para integrar estas unidades electorales.

En la región del Noreste se establecieron 47 puntos electorales, lo que implicaba otros tantos puestos de seguridad ${ }^{158}$. Todo este despliegue de seguridad hubo de llevarse a cabo con el destacamento hispano-marroquí, compuesto por 364 personas. Una vez finalizado el proceso electoral se procedió al empaquetado y transporte de los resultados hasta Puerto Príncipe. Hay que destacar que la realización de las elecciones, de las que salió elegido René Préval, se llevó a cabo sin que se produjera ningún conflicto de grandes dimensiones. Asimismo, las tropas españolas pertenecientes a la FIMEX-H, ante la escasa presencia de organizaciones humanitarias en esa zona del país, llevó a cabo labores humanitarias a través del reparto de alimentos procedentes de España y la asistencia sanitaria a la población local. La estancia de las tropas españolas en Haití bajo el paraguas de las MINUSTAH finalizó el 26 de mar-

\footnotetext{
155 Entre Fort Liberté y Ouanaminthe hay 22 kilómetros.

156 Lunes y viernes.

157 REDACCIÓN., «Dos muertos en Haití durante una revuelta contra la que actuaron tropas españolas», El Confidencial.com, artículo publicado el 13 de enero de 2006.

${ }^{158} \mathrm{La}$ prelación de seguridad se realizó cromáticamente, indicando el verde, amarillo y rojo los diferentes niveles.
} 
zo de 2006, con la ceremonia de transferencia de autoridad, celebrada en la «Base Cervantes», a las fuerzas armadas uruguayas.

A modo de conclusión decir que la Armada española, a través de sus más de 1.000 Infantes de Marina destacados, estuvo presente en el país durante 18 meses. En relación con el despliegue de la FIMEX-H, el Coronel de Infantería de Marina, Gacio Painceira dijo sobre Haití y su población:

«A la mayoría de los que allí estuvimos nos impactaron las condiciones de vida de los haitianos. Pudimos ver sus casas, en las que no había casi de nada, pudimos ver sus paisajes, bellos pero infra desarrollados, y pudimos conocer a sus gentes; la mayoría buena gente. Hicimos lo posible para enseñarles a encontrar un futuro próspero y pacífico, aunque la sensación al salir de allí fue la de haberles dejado a sus expensas. A cambio, ellos también nos enseñan algo: que se puede ser feliz con muy poco» ${ }^{159}$.

\section{Consideraciones finales: ¿ES VÁlido el actual modelo de Gestión DE LAS NACIONES UNIDAS FRENTE A LA SITUACIÓN HAITIANA?}

Las Naciones Unidas no pueden dejar pasar la oportunidad de demostrar al mundo a través de su intervención en Haití que su modelo de gestión para solventar las crisis internacionales puede resultar efectivo y adecuado en ámbitos como la consolidación de la paz, el respeto a los derechos humanos y el desarrollo en aquellos lugares que más lo necesitan ${ }^{160}$.

En nuestra opinión, en caso de no se logre este objetivo, las consecuencias para el sistema actual de mediación de conflictos de las Naciones Unidas podrían ser muy perniciosas al verse seriamente desprestigiado y deslegitimado, dando aún más la razón a aquellos que solicitamos que la necesaria reforma institucional de las Naciones Unidas se acelere ${ }^{161}$.

No debemos olvidar que la respuesta del sistema de las Naciones Unidas ante las crisis haitianas ha garantizado durante más de diez años unas condiciones de paz y estabilidad que han servido de base para importantes avances

\footnotetext{
159 GonZález HernándeZ, M. y Manero Salvador, A., op. cit., p. 185.

160 Ramón Chornet, C., Conflictos armados: de la vulneración de los Derechos Humanos a las sanciones del Derecho Internacional, Tirant lo Blanch, Valencia, 2014, pp. 121-127.

161 Bermejo García, R. y LóPEZ-Jacoiste Díaz, M. A., «La reforma institucional de las Naciones Unidas», UNISCI Discussion Papers, $\mathrm{n}^{\circ} 10$ (2006), pp. 23-73.
} 
en otros ámbitos. Sin embargo, una vez más y a raíz de las fallidas elecciones presidenciales de octubre de 2015, la comunidad internacional se encuentra en una situación complicada en la que debe ejercer de mediador con el fin de que el proceso democrático que se inició en el año 2004 no descarrile una vez más.

Hemos de poner de manifiesto la excesiva complejidad institucional y electoral establecida por la Constitución haitiana del año 1987. El profesor Anthony P. Maingot ya afirmaba en el año 1998 que «el sistema electoral es de una complejidad tal que no existe la capacidad, técnica o financiera del Estado haitiano para manejarlo» ${ }^{162}$. Esta reflexión, de radiante actualidad, no solamente ilustra con claridad la problemática endémica del sistema electoral haitiano, sino que pone asimismo en evidencia la ausencia de capacidad de la administración nacional haitiana para gestionar de una manera eficaz la complejidad electoral derivada de su estructura institucional. A la vista de las circunstancias sería coherente indicar que el sistema de Naciones Unidas no ha sido capaz de revertir a lo largo de los años las principales circunstancias que periódicamente provocan la parálisis del sistema democrático de Haití.

El problema relativo a la complejidad del sistema electoral del país surge del hecho que el legislador haitiano quiso dotarse de un instrumento tan extremadamente garantista que dificulta considerablemente que un país en las circunstancias de Haití pueda cumplir con los requisitos electorales establecidos por su ordenamiento jurídico, y en última instancia disponer de un poder democrático legitimado mediante las urnas. El elevado número de citas electorales establecidas en periodos diferentes, la multitud de órganos creados o que han de crearse, y la falta de recursos técnicos y económicos son los principales obstáculos a los que se enfrenta el país. El sistema tal y como está organizado en la actualidad no será sostenible una vez finalice el apoyo de la comunidad internacional al país ${ }^{163}$. En este sentido, y en aras de lograr la consolidación de Haití como una nación democrática autónoma, sería reco-

162 Rial Roade, J. y ZovatTo G. D., Elecciones y democracia en América Latina, 1992-1996: urnas y desencanto político, Instituto Interamericano de Derechos Humanos, Centro de Asesoría y Promoción Electoral, 1998, p. 135.

163 S/2015/667, Informe del Secretario General sobre la Misión de Estabilización de las Naciones Unidas en Haití, 31 de agosto de 2015. Además de la suma de 13,82 millones de dólares ya aportados al fondo colectivo para las elecciones administrado por el PNUD, el Gobierno asignó 24,5 millones de dólares. En una reunión de los asociados internacionales celebrada el 16 de julio se recaudaron otros 14,5 millones de dólares para el fondo colectivo y para la Oficina de las Naciones Unidas de Servicios para Proyectos, lo que dejó un déficit de financiación de 21,8 millones de dólares para la conclusión del ciclo electoral. 
mendable simplificar el sistema establecido por su norma fundamental. Es de lamentar la oportunidad perdida en el año 2012 cuando se procedió a reformar la Constitución de 1987 en una serie de ámbitos y se dejó de lado el sistema electoral ya que se realizó una reforma de mínimos por la falta de consenso para abordar temas estructurales ${ }^{164}$.

En este sentido, la ONU únicamente puede acompañar a Haití en el proceso. Cualquier otra iniciativa de la comunidad internacional tendente a modificar la norma fundamental del país podría ser considerada como una injerencia inaceptable en su soberanía nacional, lo que daría pie a que aquellos que pretenden mostrar la MINUSTAH como una fuerza de ocupación al servicio de intereses extranjeros utilizaran la modificación constitucional como argumento a su favor.

Las Naciones Unidas se encuentran en una difícil tesitura en estos momentos. Es evidente que su presencia militar y policial no puede perpetuarse en Haití, como lo es asimismo que no está en posición de hacer frente sine die a las constantes cargas económicas que derivan de la complejidad de los procesos electorales que se producen el país. Haití debe entender que la consolidación democrática no puede recaer únicamente sobre las espaldas de la comunidad internacional, por lo que deben adoptar medidas para ser capaces de gestionar ellos mismos estos procesos democráticos en base a unos criterios de libertad y transparencia. Así pues, resulta de muy poca ayuda el hecho de que unas elecciones como las que se produjeron en octubre de 2015, respaldadas por las misiones de observación electoral de la Unión Europea y la Organización de los Estados Americanos, no prosperaran debido al bloqueo institucional de la oposición y a la utilización de la violencia por sus seguidores ${ }^{165}$.

Haití, una vez más está entrando en una peligrosa espiral de deslegitimación y violencia que puede desembocar en el fracaso de los esfuerzos llevados a cabo por el sistema de las Naciones Unidas desde hace ya más de diez años ${ }^{166}$. Hace unos meses podía considerarse que el modelo de gestión de las Naciones Unidas, a pesar de sus deficiencias, había logrado el objetivo propuesto de consolidar la paz y la democracia en el país. En noviembre de 2016, y dadas las

\footnotetext{
${ }^{164}$ Loi constitutionnelle portant amendement de la Constitution de 1987, Le Moniteur, No. 98, 19 Juin 2012.

$165 \mathrm{~S} / 2016 / 225$, op. cit., párrafos 5-11.

166 Bermejo García, R. y LóPEZ-Jacoiste Díaz, E., «Un mundo más seguro: la responsabilidad que compartimos, informe del Grupo de Alto Nivel sobre las amenazas, el desafío y el cambio a modo de introducción», Anuario Español de derecho internacional, $\mathrm{n}^{\circ}$ 21, 2005.
} 
actuales circunstancias se puede afirmar que el sistema está en entredicho. Los próximos meses serán clave para determinar si una vez más la MINUSTAH es capaz de adaptarse a las nuevas circunstancias que se producen y enderezar la situación.

En este sentido, el Consejo de Seguridad, a través de la Resolución 2313 (2016), ha considerado oportuno prolongar la presencia de las tropas de la ONU en Haití hasta el 15 de abril de 2017 con el fin de hacer frente a las amenazas que en materia de consolidación democrática y seguridad se ciernen sobre el país. Será a partir de esta fecha cuando, en base al informe correspondiente a realizar sobre la «capacidad general de Haití de garantizar la seguridad y la estabilidad y de las condiciones de seguridad sobre el terreno» ${ }^{167}$, las Naciones Unidas entren a considerar una posible retirada de la MINUSTAH y un nuevo marco que regule «una futura presencia de las Naciones Unidas» en el país.

Si no se apuntaban los logros conseguidos se corre el riesgo, como ya ocurrió en el año $1997^{168}$, de volver a prácticas y comportamientos del pasado que, además de menguar la credibilidad del sistema de resolución de conflictos de las Naciones Unidas, echarían por tierra el trabajo desarrollado en Haití desde hace más de diez años por parte de la comunidad internacional.

\footnotetext{
167 S/RES/2313 (2016), op. cit., párrafo 4.

168 A/52/499, Asamblea General, Quincuagésimo segundo período de sesiones, Situación de los derechos humanos en Haití, Nota del Secretario General, 17 de octubre de 1997, párrafos 96-99.
} 